Published in "Chemical Society Reviews 47(6): 2145-2164, 2018"

which should be cited to refer to this work.

\title{
The emerging era of supramolecular polymeric binders in silicon anodes
}

\begin{abstract}
Tae-woo Kwon, ${ }^{\mathrm{a}}$ Jang Wook Choi (D)*b and Ali Coskun (D)*ac
Silicon (Si) anode is among the most promising candidates for the next-generation high-capacity electrodes in $\mathrm{Li}$-ion batteries owing to its unparalleled theoretical capacity $\left(4200 \mathrm{~mA} \mathrm{~h} \mathrm{~g}^{-1}\right.$ for $\left.\mathrm{Li}_{4.4} \mathrm{Si}\right)$ that is approximately 10 times higher than that of commercialized graphitic anodes ( $372 \mathrm{~mA} \mathrm{~h} \mathrm{~g}^{-1}$ for $\mathrm{LiC}_{6}$ ). The battery community has witnessed substantial advances in research on new polymeric binders for silicon anodes mainly due to the shortcomings of conventional binders such as polyvinylidene difluoride (PVDF) to address problems caused by the massive volume change of Si (300\%) upon (de)lithiation. Unlike conventional battery electrodes, polymeric binders have been shown to play an active role in silicon anodes to alleviate various capacity decay pathways. While the initial focus in binder research was primarily to maintain the electrode morphology, it has been recently shown that polymeric binders can in fact help to stabilize cracked Si microparticles along with the solid-electrolyte-interphase (SEI) layer, thus substantially improving the electrochemical performance. In this review article, we aim to provide an in-depth analysis and molecular-level design principles of polymeric binders for silicon anodes in terms of their chemical structure, superstructure, and supramolecular interactions to achieve good electrochemical performance. We further highlight that supramolecular chemistry offers practical tools to address challenging problems associated with emerging electrode materials in rechargeable batteries.
\end{abstract}

${ }^{a}$ Graduate School of Energy, Environment, Water and Sustainability (EEWS), Korea Advanced Institute of Science and Technology (KAIST), Daejeon 34141, Republic of Korea

${ }^{b}$ School of Chemical and Biological Engineering and Institute of Chemical Processes, Seoul National University, 1 Gwanak-ro Gwanak-gu, Seoul 08826, Republic of Korea. E-mail: jangwookchoi@snu.ac.kr

Department of Chemistry, University of Fribourg, Chemin de Musee 9, Fribourg1700, Switzerland. E-mail: ali.coskun@unifr.ch

\section{Introduction}

Environmental problems such as global warming and ocean acidification originating from anthropogenic $\mathrm{CO}_{2}$ emissions present a substantial challenge for the human race and necessitate the advancement of technologies utilizing renewable energy. In particular, the intermittent nature of renewable energy 
sources requires advanced electrochemical energy storage systems represented by rechargeable batteries. While these systems could be used at a grid scale, ${ }^{1}$ just like a recent example in South Australia, they are also urgently needed for the timely advent of advanced portable devices and electric vehicles (EVs). ${ }^{2,3}$ Although rechargeable lithium-ion batteries have successfully penetrated consumer markets mainly based on high energy densities and other balanced electrochemical properties, ${ }^{2,4}$ their energy densities available with conventional electrode materials are close to saturation; graphitic anodes can store only 1 lithium ion per 6 carbons $\left(\mathrm{LiC}_{6}\right)$ corresponding to a gravimetric capacity of $372 \mathrm{~mA} \mathrm{~h} \mathrm{~g}^{-1}$. In an effort to further increase the specific capacity, various anode materials ${ }^{5}$ capable of storing more lithium ions per unit mass or unit volume have been explored (Fig. 1A). Among the promising candidates, silicon ( $\mathrm{Si}$ ) holds the advantages of high theoretical capacity (3579-4200 $\mathrm{mA} \mathrm{h} \mathrm{g}{ }^{-1}$ for $\mathrm{Li}_{15} \mathrm{Si}_{4}-\mathrm{Li}_{4.4} \mathrm{Si}$ ) as well as low operation voltage $\left(0.4\right.$ versus $\left.\mathrm{Li} / \mathrm{Li}^{+}\right)$, abundant resources (the second largest in the earth's crust), and environmental benignity (non-toxic). Furthermore, the semiconductor industry is at the mature stage, which is beneficial in reducing the cost for processing Si. Therefore, Si is recognized as one of the most promising anode materials to replace the existing graphitebased anode materials in the near future.

Despite all the aforementioned benefits, however, Si anodes suffer from chronic capacity fading during cycling, which results from the immense volume change of Si (up to $300 \%){ }^{4,6-22}$ The volume expansion of $\mathrm{Si}$ is accompanied by lithium ion insertion (lithiation) into Si during charging. The volume of Si contracts upon extracting lithium ions (delithiation) during discharging. In the given process, a significant volume change of $\mathrm{Si}$ is inevitable, leading to several problems (Fig. 1B). ${ }^{5}$ Firstly, the repeated volume change of $\mathrm{Si}$ loosens the particle-to-particle contacts, resulting in the electrical isolation of Si particles and delamination of the electrode from the current collector.
Secondly, an unstable and thick solid electrolyte interphase (SEI) layer is formed. Under reductive potentials, organic electrolytes are subject to decomposition via charge transfer at the electrode surface, which leads to the formation of a SEI layer. The iterative volume change of Si breaks the SEI layer, leading to the formation of an additional SEI layer on the fresh Si surface. This process continuously consumes $\mathrm{Li}$ ions as well as the electrolyte, thus impairing the Coulombic efficiency in each cycle and ultimately exhausting the electrolyte. Lastly, while Si nanoparticles with a diameter below $\sim 150 \mathrm{~nm}$ are known to sustain the mechanical stress due to the size effect, $\mathrm{Si}$ (sub)microparticles cannot do so and are pulverized. ${ }^{23-25}$ These pulverized Si particles are scattered to become electrically isolated or cause further growth of SEI layers due to the increased surface area. Although it appears that the binder alone cannot prevent Si microparticles from pulverization, well-designed binders can alleviate the side effects of the pulverization and improve the cell performance significantly. ${ }^{26-30}$

In this review, we aim to present an in-depth analysis of polymeric binders and provide insights on their design principles in relation to the electrochemical performance of Si anodes. In a broader context, we also demonstrate how molecular-level design of various supramolecular interactions on polymeric binders can be directly translated into an improved electrochemical performance in $\mathrm{Si}$ anodes. We begin by discussing the intermolecular bond strength of polymeric binders, varying from strong covalent bonding to weak noncovalent interactions. The critical role of strong supramolecular interactions is highlighted in comparison to both weak supramolecular interactions and covalent crosslinking. Subsequently, we also address the impact of polymer architectures as well as their superstructures. In comparison to linear polymers, branched polymers clearly offer more robust scaffolds to suppress the movement of Si particles. We also discussed the working principle and advantages of conductive binders. Finally, we introduce the concept of topological crosslinking that endows binders with high elasticity and tolerance for the high stress originating from the volume change of Si microparticles during cycling.

\section{Impact of polymer interactions}

The basic role of a binder in an electrode is the cohesion of the electrode components (e.g., active material and conductive agent) and their adhesion to a current collector during the cell operation. In this regard, binder is expected to play a pivotal role in the mechanical stability of Si electrodes and their long-term cycling performance. In this context, enhancing the adhesion strength of binders with Si particles would be a good starting point in the design of polymeric binders.

The adhesion strength of polymers is closely associated with their chemical nature. The chemical bonds can be divided into three categories in terms of their reversibility and strength: weak supramolecular interactions, strong supramolecular interactions including coordination bonds, and covalent bonds (Fig. 2A). These three categories respond differently to external 


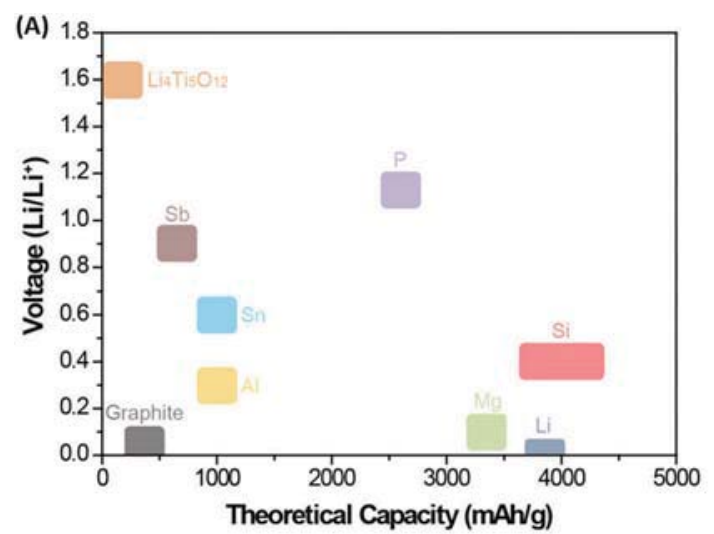

(B)
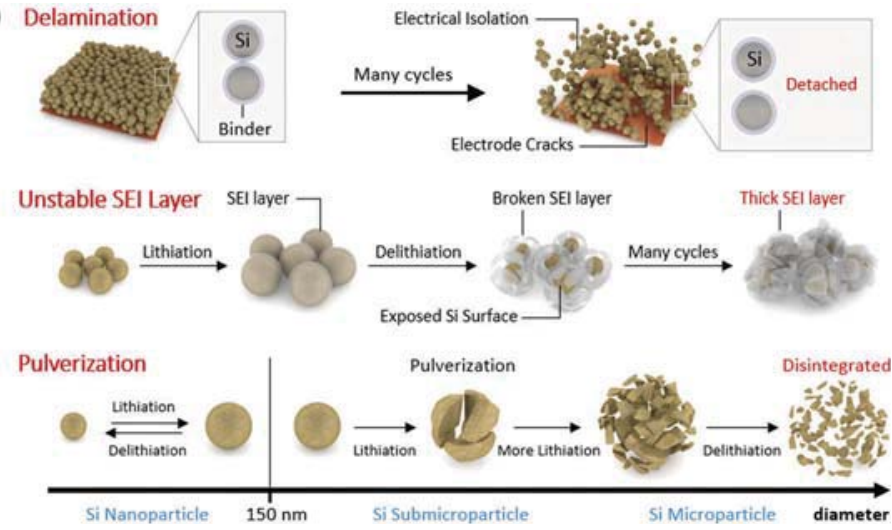

Fig. 1 (A) Operating voltages and theoretical capacities of various anode active materials for lithium-ion batteries. (B) Three representative failure mechanisms of Si anodes: delamination, unstable SEl layer, and pulverization.
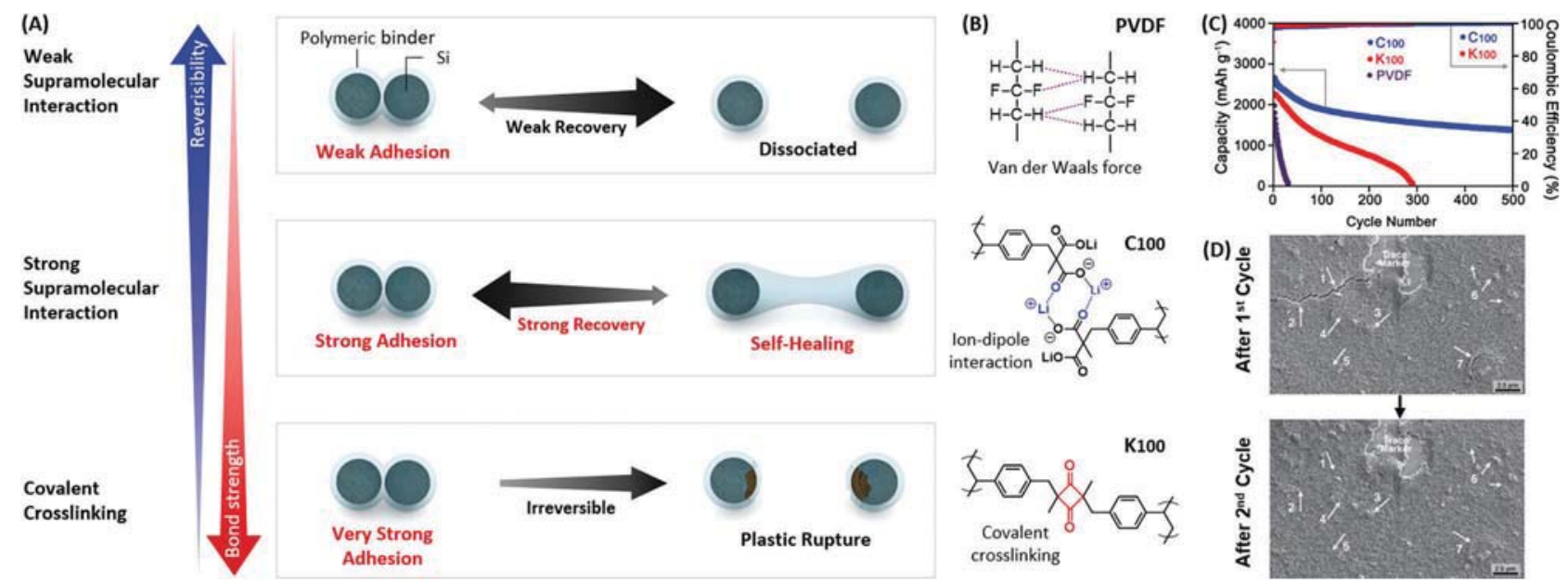

Fig. 2 (A) Classification of chemical bonds and supramolecular interactions and their adhesion behaviors in Si anodes. (B) Three types of representative polymeric binders for different classes of bonding. (C) Cycling performance of Si anodes with PVDF, $\mathrm{C}_{100}$, and $\mathrm{K}_{100}$. The Si anodes were prepared by containing $60 \mathrm{wt} \% \mathrm{Si}$ (diameter: $\sim 90 \mathrm{~nm}$, loading: $0.2 \mathrm{mg} \mathrm{cm}^{-2}$ ), $20 \mathrm{wt} \%$ Super P, and $20 \mathrm{wt} \%$ binder. The current density was $3000 \mathrm{~mA} \mathrm{~g}{ }^{-1}$. (D) SEM images of $\mathrm{C}_{100}-\mathrm{Si}$ after the 1st and 2nd cycle. (C and D) Adapted from ref. 31 with permission from Wiley-VCH Verlag GmbH \& Co., copyright 2014.

mechanical stress. Unlike covalent bonds, supramolecular interactions inherently have a reversible bonding nature; supramolecular interactions tend to be dissociated rather than ruptured under applied stress and the bonds can be recovered upon the elimination of the stress. Fascinatingly, this reversibility in bonding serves as the basis for realizing the self-healing effect. The efficiency of bond recovery depends on the strength of supramolecular interactions. For example, weak supramolecular interactions (e.g. van der Waals force) can readily dissociate even under small mechanical stress. Although this weak bonding leads to high reversibility, the driving force to recover is also weak. On the other hand, strong supramolecular interactions (e.g. hydrogen bonding and iondipole interaction) recover dissociated bonds more efficiently due to their reversibility and stronger bonds. Lastly, covalent bonds cannot be recovered upon rupture and are thus unable to self-heal. While the formation of a relatively stiff network structure through covalent crosslinking can suppress the detachment of active particles, the irreversible bond breakage during repeated volume change of Si eventually leads to electrode failure.

The systematic study performed by Kwon et al. revealed how these three types of chemical bonds affect the performance of polymeric binders in $\mathrm{Si}$ anodes and also identified the key parameter for binder performance, that is self-healing. ${ }^{31}$ They prepared three polymeric binders: polyvinylidene fluoride (PVDF), $\mathrm{C}_{100}$, and $\mathrm{K}_{100}$ as binders with weak supramolecular interactions, strong supramolecular interactions, and covalent crosslinking, respectively (Fig. $2 \mathrm{~B}$ ). It should be noted that $\mathrm{K}_{100}$ has no strong supramolecular interaction except covalent crosslinking and covalent attachment to the silicon surface.

The galvanostatic measurements of Si anodes incorporating these binders (denoted as binder-Si in this review for simplicity) showed distinct outcomes in their electrochemical performance (Fig. 2C). The capacity of PVDF-Si rapidly dropped within the early stages of cycling owing to its weak van der Waals interactions, which are not strong enough to preserve the particle-particle cohesion under the massive volume change of Si. 
$\mathrm{K}_{100}-\mathrm{Si}$ exhibited better cycling performance compared to that of PVDF-Si, which is attributed to strong covalent crosslinking that can form a stiff three-dimensional polymer network, efficiently suppressing the effect of the volume expansion of $\mathrm{Si}$. However, its irreversible bonding nature, albeit strong, can be gradually deteriorated over cycling, resulting in plastic damage. ${ }^{31,32}$ On the other hand, $\mathrm{C}_{100}-\mathrm{Si}$ showed the best cycling performance due to the self-healing effect originating from ion-dipole interactions even though the bond strength of $\mathrm{C}_{100}$ is weaker than that of $K_{100}$. This study shows that the balance between the self-healing effect and bond strength is essential for superior cycling performance. Tracing the surface morphology of the electrode (Fig. 2D) by scanning electron microscopy (SEM) revealed the working principle of $\mathrm{C}_{100}-\mathrm{Si}$; cracks are formed in cell operation during the 1st cycle, but the generated cracks (white arrows in Fig. 2D) spontaneously closed up after the 2 nd cycle by virtue of the reversible ion-dipole interactions of $\mathrm{C}_{100}$.

Combining these results, it can be concluded that increasing bond strength is desirable up to a certain point as long as the self-healing ability is not impinged upon. In this regard, polymeric binders with weak supramolecular interactions are not capable of maintaining the physical integrity of Si anodes, but neither are those with covalent crosslinking, as the bonds are too strong for the desired self-healing to take effect. Therefore, the strong supramolecular interactions would be an ideal class of bonding system suited for $\mathrm{Si}$ anodes in that the strong adhesion and self-healing ability can be realized spontaneously. The introduced binders in the following section are based on this principle.

\subsection{Sodium carboxymethyl cellulose (CMC)}

CMC is a representative binder featuring strong noncovalent interactions such as ion-dipole and hydrogen bonding interactions. CMC is a linear polysaccharide, a derivative of cellulose, consisting of $\beta$-linked glucopyranoses with carboxymethyl substitution (Fig. 3). Prior to Si-based anodes, CMC was first applied to graphite anodes in order to facilitate the aqueous processing of graphite particulates in $2005 .{ }^{33,34} \mathrm{CMC}$ was found to be a good dispersant for the graphite particles in an aqueous medium. This phenomenon was attributed to the polymer structure, that is, the hydrophobic parts of CMC can adsorb onto the hydrophobic graphite surface whereas the charged carboxylate groups of the adsorbed CMC layer stabilize the graphite surface in water (Fig. 3A). Thus, CMC acts like a surfactant. Additionally, it was also found that mixing emulsified styrene butadiene rubber (SBR) with CMC led to a more homogeneous and less porous microstructure of $\mathrm{Si} /$ graphite anodes, as compared with CMC or SBR alone. This is ascribed to the surface modification of the graphite particles, in which the mixture of CMC and SBR at a certain ratio greatly increases the surface charge of the graphite as demonstrated by the electrokinetic measurements. ${ }^{33}$

The idea of using an elastomeric binder ${ }^{35,36}$ to accommodate the massive volume change prompted the utilization of $\mathrm{CMC} / \mathrm{SBR}$ for carbon-coated $\mathrm{Si}$ anodes in $2005 .{ }^{37}$ In contrast to $\mathrm{PVDF}, \mathrm{CMC} / \mathrm{SBR}$ showed small modulus, high elasticity,

\section{(A) CMC-Graphite}

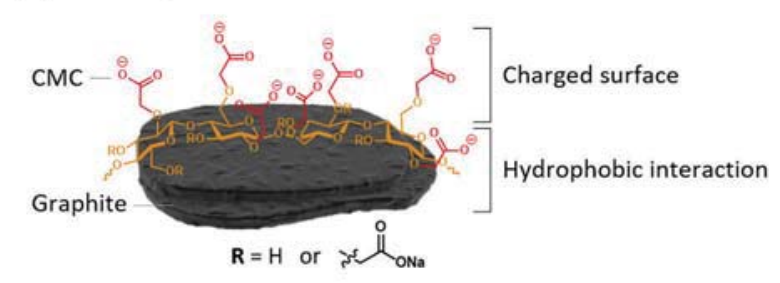

(B) CMC-Si

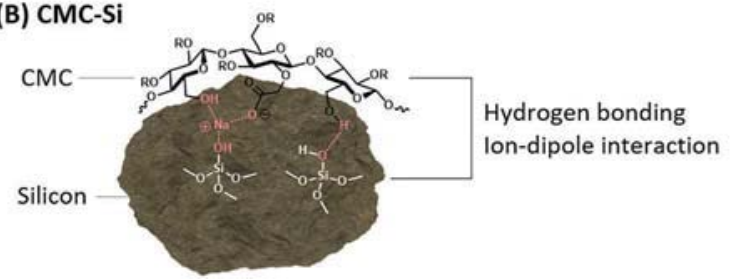

Fig. 3 Structural characteristics and interactions of CMC with active materials: (A) graphite with hydrophobic surface and (B) silicon with hydrophilic surface.

strong adhesion, and low electrolyte uptake. Such good mechanical properties improved the adhesion and capacity retention of Si anodes. In 2006, the CMC/SBR binder was further studied for Si/graphite and exclusive graphite anodes. ${ }^{38}$ For exclusive graphite anodes, SBR/CMC-graphite (SBR: CMC = 5:1 wt\%) showed better cycling performance compared to CMC-graphite and SBR-graphite. For Si/graphite anodes (Si : Graphite = 10:90 wt\%), CMC/SBR and CMC apparently increased the specific capacity in comparison to PVDF, but the cycling efficiencies of CMC/SBR and CMC were similar unlike the trend in the exclusive graphite anode. This implies that the effect of binders is quite different in graphite and $\mathrm{Si} /$ graphite anodes, as $\mathrm{Si}$ and graphite have different physical and chemical surface properties (Fig. 3). Another hybrid binder (CMC/acrylic adhesive LA132) was reported by Chen et al. ${ }^{39}$ The CMC/LA132-Si/graphite, where Si and graphite are embedded in poly(vinyl chloride) (PVC) pyrolyzed carbon, showed the best cycling performance among PVDF, LA132, and CMC/LA132 due to the enhanced adhesion strength and lower solvent uptake.

The CMC binder for pure $\mathrm{Si}$ anodes was investigated by $\mathrm{Li}$ et $a l .{ }^{40}$ The key message in the given work was that the capacity retention of the CMC-Si anode is better than that of the $\mathrm{CMC} /$ SBR-Si counterpart. This result is completely against the previous understanding that elastomeric binders are ideally suited for large-volume-change electrodes. ${ }^{35,36}$ While they could not identify the exact mechanism on why stiff CMC shows better cycle life than that of less stiff CMC/SBR, the tensile test of the binder films showed that the CMC/SBR was not elastic enough, giving a partial clue for the unexpected cyclability results. In the following studies, substantial efforts have been made to elucidate this phenomenon. Lestrietz et al. attributed the high performance of $\mathrm{CMC}$ to the extended conformation by means of the stiff cellulose backbone and the electrostatic repulsion of carboxylate groups. ${ }^{41}$ The extended conformation is expected to increase the number of interaction points between polymers and $\mathrm{Si}$, which leads to more stable electrode integrity. More viscous 
and homogeneous mixtures of binder/conductive agent were achieved by using CMC, compared to other flexible binders tested: PVDF, poly(vinyl pyrrolidone) (PVP)/ethylene glycol (EG)/TX100, and CMC/poly(ethylene-co-acrylic acid) (PEAA). Besides, Bridel et al. proposed the self-healing concept of CMC that contributes to the improvement of cell performance. ${ }^{42}$ As shown in Fig. 3B, hydroxyl and carboxylate groups of CMC can form hydrogen bonding and ion-dipole interactions with the silanol groups of the native oxide layer formed on the Si surface. These strong supramolecular interactions can be dissociated and reformed again, achieving the desired self-healing effect. They proved the self-healing property by the following methods. First, they intentionally damaged the CMC-Si by mild hand milling and confirmed that the electrode performance was fully recovered after processing in water thanks to the inherent reversibility of supramolecular interactions. Second, when they removed the hydroxyl groups from the Si surface by grafting propyltriethyoxysilane, in which CMC can weakly interact with nonpolar alkyl chains of Si via only van der Waals forces, the cell performance clearly deteriorated. These findings suggest that strong supramolecular interactions between binder and $\mathrm{Si}$ is critical for good cycling performance. Finally, when they covalently linked CMC and Si surface via peptidic bonds, this yielded worse cell performance. Therefore, for Si-binder interaction, as in binder-binder interaction, ${ }^{31}$ the strong supramolecular interaction is more desirable for stable cycling performance.

The importance of porosity in CMC-Si was unveiled as a key parameter to accommodate the volume changes of $\mathrm{Si}^{42,43}$ Guo et al. prepared a porous CMC scaffold using a slurry spray technique. The slurry containing aqueous mixture of $\mathrm{Si}$, carbon black, and CMC was sprayed onto a pre-heated copper current collector. The water is immediately evaporated from the copper current collector, generating a porous scaffold structure. Si particles can expand and contract within the pores and buffer the mechanical stress, which leads to a more stable cyclability compared to that of the non-porous counterpart. ${ }^{44-46}$ This strategy is likely to be more effective for stiff/brittle binders (such as CMC) because they cannot buffer high strain caused by the massive volume change of Si.

\subsection{Poly(acrylic acid) (PAA)}

Pure PAA was examined as a binder for Si anodes by Magasinski et $a l^{47}$ PAA is composed of carboxylic acids that can form strong hydrogen bonding interactions between binder-binder and binder-Si (Fig. 4A). Notably, the mechanical properties of the PAA before and after swelling in the electrolyte did not change much, meaning that the adhesion in the presence of electrolyte is retained. Although the interactions of PAA and CMC are analogous, PAA-Si showed better cycling performance compared to $\mathrm{CMC}-\mathrm{Si}$ in the given work. They attributed this phenomenon to the higher density of carboxylic acid moieties in PAA compared to CMC.

Additionally, PAA was also applied to SiO anodes by Komaba et al. $^{48}$ The SiO active material is composed of Si nano-domains in the $\mathrm{SiO}_{2}$ matrix. This material undergoes smaller volume expansion and enables more stable cyclability in comparison to bare Si counterpart. ${ }^{49}$ However, the volume change of SiO is still quite substantial; thus, the electrochemical performance is highly dependent on the selection of binders. Compared to PVDF, CMC, and poly(vinyl alcohol) (PVA), PAA exhibited prolonged cycle life due to strong adhesion with SiO via hydrogen bonding, limited swelling in the electrolyte solution, and lower throughthickness electric resistance.

\subsection{Sodium alginate (Alg)}

Kovalenko et al. demonstrated that Alg is a promising binder for Si anodes. ${ }^{50} \mathrm{Alg}$ is a natural polysaccharide, consisting of $\beta$-D-mannuronic acid and $\alpha$-L-guluronic acid. Analogous to the structure of $\mathrm{CMC}$, Alg also incorporates carboxylate and hydroxyl groups (Fig. 4B). These functional groups can form hydrogen bonding and ion-dipole interactions between polymer chains and with Si particles. A high density of carboxylic groups in Alg leads to a strong adhesion by providing rich anchoring points between polymer chains and Si particles. Due to its strong adhesion with $\mathrm{Si}$, Alg can remain on the Si surface even after washing with water as proven by X-ray photoelectron spectroscopy (XPS) analysis. Alg-Si anode was composed of $63.75 \mathrm{wt} \% \mathrm{Si}$ (diameter $=27 \mathrm{~nm}$, the Si loading amount is not given), $21.25 \mathrm{wt} \%$ conductive agent, and $15 \mathrm{wt} \%$ binder. Alg-Si retained 85\% $\left(1700 \mathrm{~mA} \mathrm{~h} \mathrm{~g}{ }^{-1}\right)$ of the original capacity after 100 cycles at a current density of $4200 \mathrm{~mA} \mathrm{~g}^{-1}$, while CMC-Si and PVDF-Si suffered from severe capacity fading (lower than $1000 \mathrm{~mA} \mathrm{~h} \mathrm{~g}^{-1}$ before 30 cycles).

\subsection{Catechol-functionalized binders}

In order to further increase the strength of the supramolecular interactions of PAA and Alg with $\mathrm{Si}$ particles, Ryou et al. ${ }^{51}$ covalently attached a small amount $(\sim 3 \%)$ of catechol group to PAA (PAA-C) and Alg (Alg-C) (Fig. 4C). Notably, the binding mechanism of catechol group is distinct from that of hydroxyl and carboxylate groups in that the catechol group forms strong
(A)

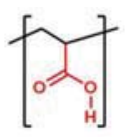

Poly(acrylic acid)
(B)

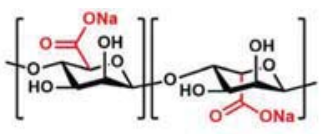

Sodium alginate
(C)

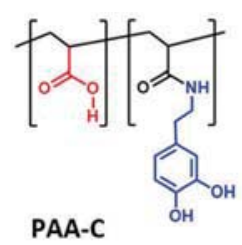

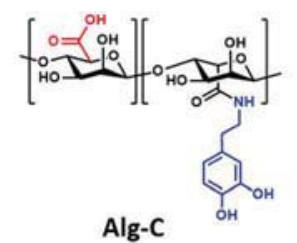

(D)

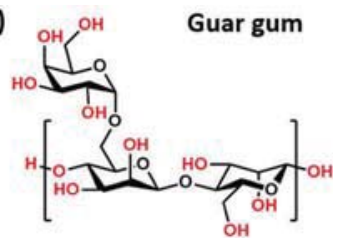

Fig. 4 Chemical structures of polymer binders: (A) poly(acrylic acid) (PAA), (B) sodium alginate (Alg), (C) catechol-functionalized PAA (PAA-C) and alginate (Alg-C), and (D) guar gum (GG). 
coordination bonds with metal oxides and this bond is reversible. ${ }^{52}$ It was reported that the bond strength of a single catechol group with titanium surface is $\sim 805 \mathrm{pN}$ (coordination bonds), which falls between hydrogen bonds (tens of $\mathrm{pN}$ ) and covalent bonds (several $\mathrm{nN}$ ). ${ }^{52}$ In accordance with this report, their actual single-molecular mechanical test using atomic force microscopy (AFM) showed that catechol-Si interaction is $\sim 750 \mathrm{pN}$, which is much stronger than hydrogen bonding and ion-dipole interactions of Alg-Si ( $\sim 73 \mathrm{pN})$. Such dual adhesion mechanism of Alg-C and PAA-C enhanced their capacities in comparison with the pristine Alg and PAA whereas their capacity retention was similar. Furthermore, the capacity increase was also observed for Alg-C-Si/graphite anode, implying that catecholic interaction is effective for $\mathrm{Si} /$ graphite blended anodes as well.

\subsection{Guar gum}

Jie Liu et al. reported guar gum (GG), ${ }^{53}$ composed of a linear backbone of $(1 \rightarrow 4)-\beta$-D-mannopyroanosyl unit with $\alpha$-D-galactopyranosyl side groups through $(1 \rightarrow 6)$ linkages (Fig. 4D), as a $\mathrm{Si}$ anode binder. Due to the large number of hydroxyl moieties on the pendant groups and the backbone, GG can interact efficiently with Si surface via hydrogen bonding and facilitate the lithium ion transfer by engaging the lone-pair electrons of the oxygen atoms. They prepared a half-cell using $53 \mathrm{wt} \% \mathrm{Si}$ $\left(\right.$ diameter $=100 \mathrm{~nm}$, Si loading $\left.=0.2-0.3 \mathrm{mg} \mathrm{cm}^{-2}\right), 18 \mathrm{wt} \%$ conductive agent (acetylene black), and $29 \mathrm{wt} \%$ binder. GG-Si anode showed high initial capacity (3364 $\mathrm{mA} \mathrm{h} \mathrm{g}^{-1}$ ) and Coulombic efficiency (88.3\%) when cycled at $2100 \mathrm{~mA} \mathrm{~g}^{-1}$ due to fast lithium-ion diffusion, while Alg-Si anode showed lower initial capacity (2195 $\mathrm{mA} \mathrm{h} \mathrm{g}^{-1}$ ) and initial Coulombic efficiency $(82.5 \%)$ under the same conditions. The superior rate capability of GG-Si to Alg-Si also supports the excellent lithium transport capability of GG. GG-Si anode retained $2222 \mathrm{~mA} \mathrm{~h} \mathrm{~g}^{-1}$ (capacity retention $=66.05 \%$ ) after 100 cycles by taking advantage of a high density of polar functional groups of GG. Together with this study, Kuruba et al. also adopted purified guar gum (PGG) as a polymeric binder for silicon-carbon composite electrodes. $^{54}$

\subsection{Urea-based binder}

Wang et al. substantially increased the efficiency of self-healing effect by using a polymeric binder with a low glass transition temperature $\left(T_{\mathrm{g}}\right) .{ }^{30}$ This self-healing polymer (SHP) was synthesized by the reaction of Empol 1016 (a mixture of diacid and triacid) with diethylenetriamine and urea (Fig. 5A). They controlled the reaction time to achieve a low $T_{\mathrm{g}}$ value below $0{ }^{\circ} \mathrm{C}$, which allows for the viscous fluidic behavior at room temperature. When the polymer layer was fractured by the mechanical stress during the expansion of $\mathrm{Si}$, the viscous flow of SHP helps
(A)

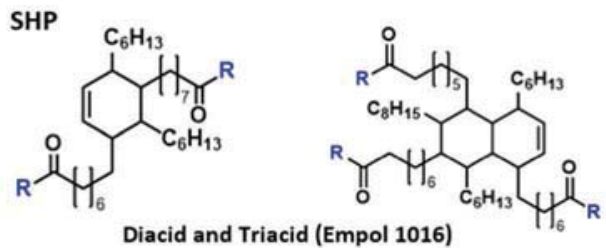

$\mathbf{R}=$<smiles>CCNC(=O)N(CC)CCNC(=O)N(CC)CC</smiles>

Urea<smiles>CC(C)NCCNCCNC(C)C</smiles>

Diethylenetriamine

(B)

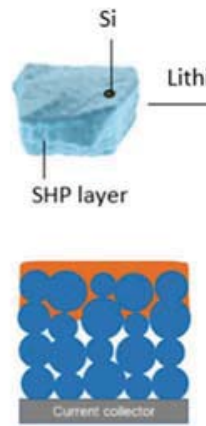

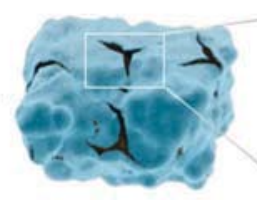
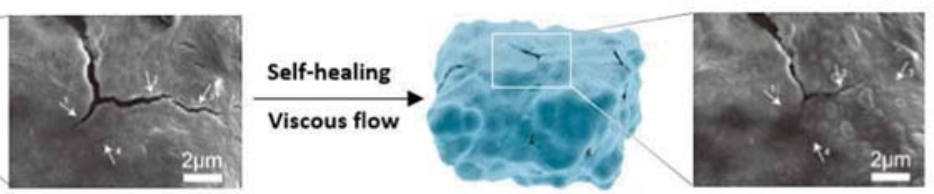

Top layer coating

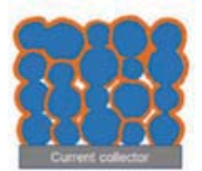

$3 \mathrm{D}$ coating

(C)

(D)

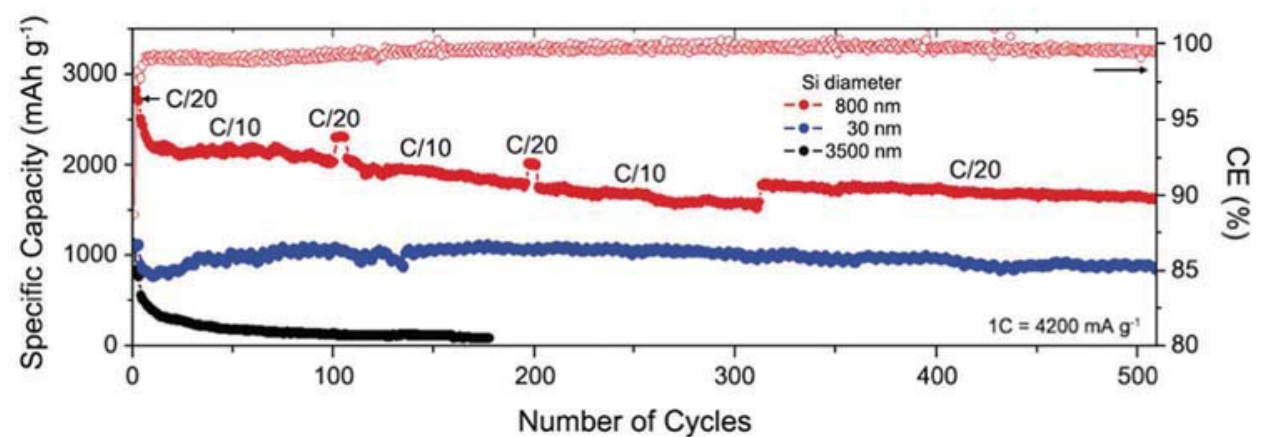

Fig. 5 (A) Chemical structure of self-healing polymer (SHP). (B) Schematic representation of the working principle and SEM images of the SHP-Si anode. Adapted from ref. 30 with permission from Nature Publishing Group, copyright 2013. (C) Coating methods of SHP. (D) Cycling performance and Coulombic efficiency (CE) of SHP-Si anode with varying size of Si particle between $30 \mathrm{~nm}$ and $3.5 \mu \mathrm{m}$. The Si anodes consist of $67 \mathrm{wt} \% \mathrm{Si}$ (loading: $0.5-0.6 \mathrm{mg} \mathrm{cm}^{-2}$ ), 4 wt\% carbon black, and 29 wt\% SHP. (C and D) Adapted from ref. 28 with permission from Wiley-VCH Verlag GmbH \& Co., copyright 2015. 
close up the cracks via self-healing engaging hydrogen bonding between urea groups as shown in SEM images (Fig. 5B). Additionally, a conductive composite of SHP and conductive agent (carbon black) coated on polydimethylsiloxane as the resilient substrate showed good electric conductivity with small hysteresis before and after 100\% elongation, although SHP itself is not resilient.

The efficient self-healing of SHP promoted the long-term cycling stability of Si microparticle (SiMP) anodes. The SiMP electrode was prepared by using $50 \mathrm{wt} \% \mathrm{Si}$ (diameter: $4.2 \mu \mathrm{m}, \mathrm{Si}$ loading amount: $0.5-0.7 \mathrm{mg} \mathrm{cm}^{-2}$ ), $7 \mathrm{wt} \%$ conductive agent (carbon black), and $43 \mathrm{wt} \%$ binder. The high binder content, although it seems necessary, is a major drawback for this particular approach. SHP-SiMP anode delivered $2094 \mathrm{~mA} \mathrm{~h} \mathrm{~g}^{-1}$ with a high retention of $80 \%$ at a current density of $400 \mathrm{~mA} \mathrm{~g}^{-1}$ after 90 cycles in contrast to those of PVDF-SiMP (14\%), CMC-SiMP (27\%), and Alg-SiMP (47\%) after 20 cycles. It is worth noting that relatively strong supramolecular interactions of urea groups, rather than the mechanical property such as low $T_{\mathrm{g}}$, is the key parameter for the stable cycling performance, which is in good accordance with other reports. ${ }^{31,55,56}$ To elaborate this view point, they also synthesized a low $T_{\mathrm{g}}$ polymer with the same structure but without urea moieties. The SiMP with this control polymer showed much worse capacity retention, indicating that urea-based hydrogen bonding is essential for the observed cycling performance.

Chen et al. further improved the electrode performance of SHP-Si anode through 3D coating of SHP onto Si particles together with the optimization of Si particle size (Fig. $5 \mathrm{C}$ ). ${ }^{28} \mathrm{In}$ the previous study, ${ }^{30}$ the $\mathrm{SHP} /$ carbon black (SHP/CB) was cast on Si particles through top layer coating, which showed limited cycling performance for thick Si anodes. They systematically examined the effect of the size of Si particles on the electrochemical performance of SHP-Si anodes. For large Si particles (Si diameter: $3.5 \mu \mathrm{m}$ ), the self-healing efficiency of SHP would be limited because pulverized small Si particles embedded in many Si fragments are isolated from the conductive pathways and SHP/CB is difficult to permeate inside. Lithium-ion diffusion is also slow due to longer diffusion trajectories inside large particles, which induced high lithiation overpotentials and low initial capacities $\left(\sim 1100 \mathrm{~mA} \mathrm{~h} \mathrm{~g}^{-1}\right)$ (Fig. 5D). On the other hand, small sized Si particles (Si diameter: $30 \mathrm{~nm}$ ) facilitate the self-healing effect, resulting in far better cycle life (no obvious capacity decay over 500 cycles). However, the initial Coulombic efficiency $(73 \%)$ and specific capacity $\left(\sim 1000 \mathrm{~mA} \mathrm{~h} \mathrm{~g}^{-1}\right)$ were lower due to larger electrode-electrolyte interface originating from increased surface-to-volume ratio. All considered, Si particles with optimum size in between small and large size is desired to achieve high specific capacity and stable cycle life. In the given study, the diameter of $800 \mathrm{~nm}$ turned out to be optimum for SHP-Si anode, showing a high capacity retention of $80 \%$ after 500 cycles. Therefore, the size of Si particles is also an important parameter to be considered for effective self-healing. Furthermore, the SHP binder was also used for a stretchable graphitic carbon/anode, ${ }^{29}$ but it appears that further improvement is needed in terms of cycle life.

\section{Impact of polymer architectures}

While the strength of a chemical bond determines the extent of interactions for each anchoring point in the binder-Si and binder-binder interactions, the polymer architecture also affects the adhesion by a different mechanism, that is, the applied mechanical force can be distributed to branched chains and the force allocated to each anchoring point can then be reduced. In this section, we address how the polymer architectures affect the electrochemical performance of Si anodes and highlight the representative polymeric binders along such perspective.

Based on the architecture, polymers can be classified into linear and branched ones (Fig. 6A). A linear polymer is a onedimensional polymer without any branches other than the pendant groups of monomers. A branched polymer is a threedimensional polymer having branching points connected by more than two polymer chains; star polymers, graft polymers, polymer networks, dendrimers, and hyperbranched polymers belong to this category.

In $\mathrm{Si}$ anodes, polymeric binders are desired to continuously dissipate the mechanical stress from the volume change of Si during repeated charge and discharge cycles. An anchoring point has a certain maximum stress limit to endure, beyond which adhesion is lost. Linear polymers directly receive the mechanical stress (Fig. 6B), where the anchoring points are subsequently detached under high mechanical stress. Consequently, linear polymer chains become mobile on the Si surface. ${ }^{57,58}$ In contrast, as for branched polymeric binders (Fig. 6C), the mechanical stress can be distributed to branched chains at the branching points, which can substantially reduce the stress applied to each anchoring point. Additionally, the manageable maximum stress of the anchoring points is increased in a way that polymer chains cooperatively resist the external force via intrachain cohesion. ${ }^{58,59}$ Such multidimensional contacts of branched polymers render them immobile and strongly adhesive on the Si surface, restraining the movement of the Si particles and extending cycle lives (Fig. 6D).

\subsection{Hyperbranched polymeric binders}

A hyperbranched polymer is one of the representative branched polymers having repetitively and randomly branched chains. Jeong et al. demonstrated that hyperbranched $\beta$-cyclodextrin polymer ( $\beta$-CDp) (Fig. 7) provides a good platform to form intimate adhesion with Si surface and preserve the mechanical integrity of the Si electrode, resulting in a stable cycle life. ${ }^{60}$ Compared to Alg as a linear polymeric binder, a higher amount of $\beta$-CDp remained on the Si surface after washing with water, reflecting the strong adhesion of $\beta$-CDp. $180^{\circ}$ peeling test also proved that hyperbranched $\beta$-CDp has strong adhesion due to its multidimensional contacts with Si particles. The electrochemical performance of the $\mathrm{Si}$ anodes was examined using a half-cell consisting of $60 \mathrm{wt} \% \mathrm{Si}$ (diameter $=120-200 \mathrm{~nm}$, Si loading $=0.6 \mathrm{mg} \mathrm{cm}^{-2}$ ), $20 \mathrm{wt} \%$ conductive agent (Super P), and $20 \mathrm{wt} \%$ binder. $\beta$-CDp-Si exhibited good cycling performance of $50.6 \%$ retention after 150 cycles at a current density of $4200 \mathrm{~mA} \mathrm{~g}^{-1}$, while the capacity retention of Alg-Si was only $27.1 \%$. They further 

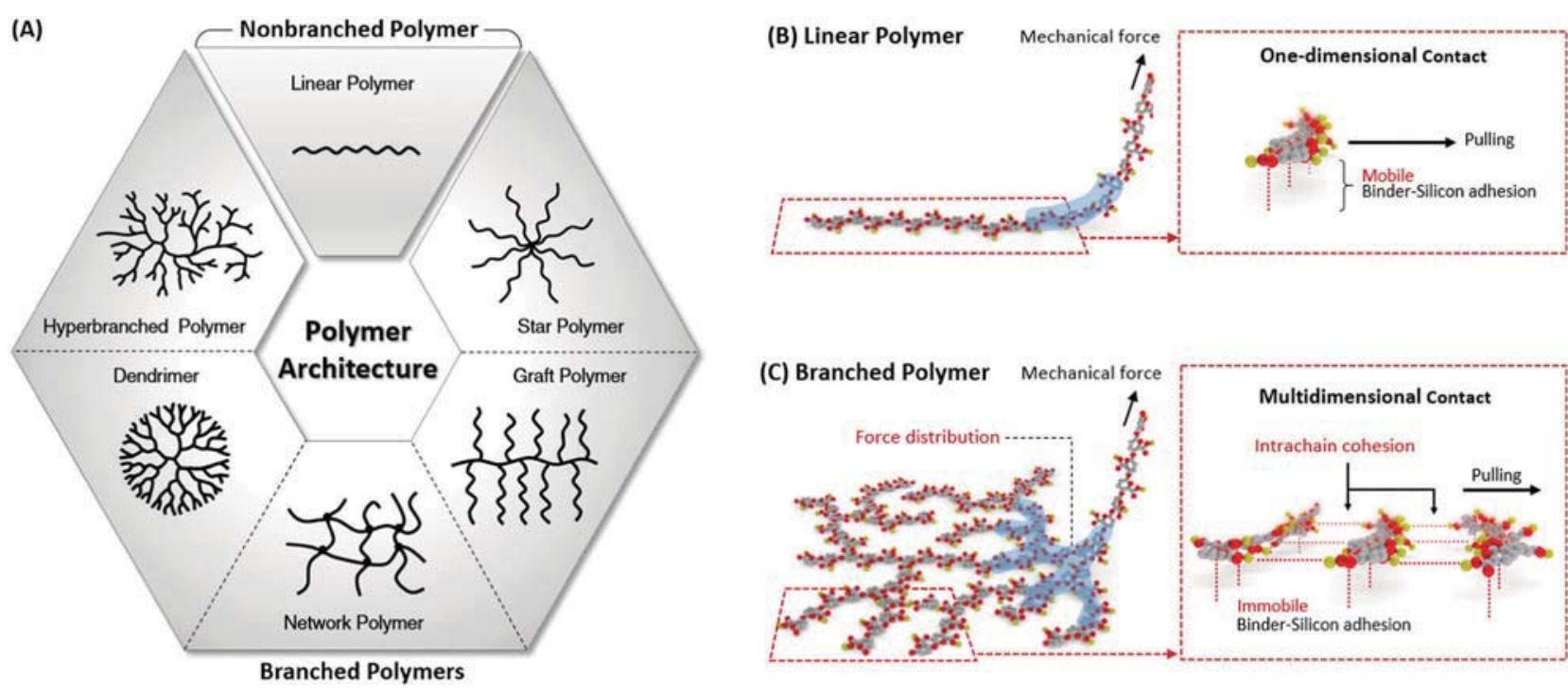

(D)

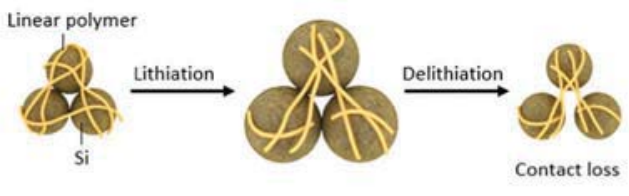

Linear Polymeric Binders

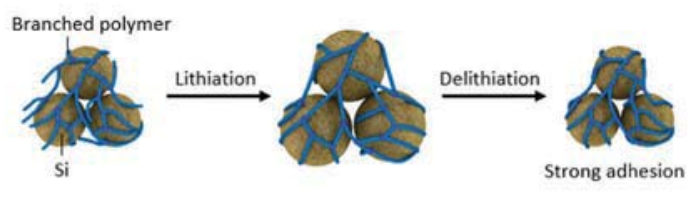

Branched Polymeric Binders

Fig. 6 (A) Classification of polymers in terms of polymer architecture. (B) Response of linear polymers against mechanical force. (C) Response of branched polymers against mechanical force. (D) Adhesion behaviour of linear and branched polymeric binders in Si anodes.

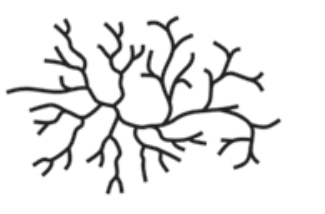

Hyperbranched Polymer

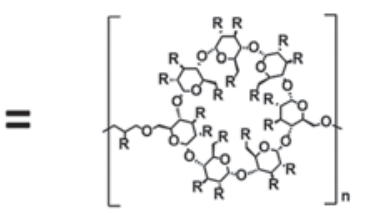

$\beta$-Cyclodextrin polymer

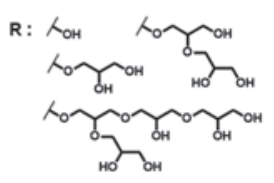

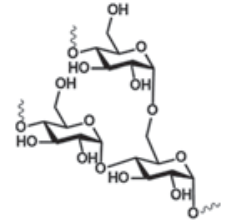

Amylopectin / glycogen

Fig. 7 Hyperbranched polymeric binders: $\beta$-cyclodextrin polymer ( $\beta$-CDp), amylopectin, and glycogen.

improved the electrode performance by using a hybrid binder of $\beta$-CDp/Alg that increases the number of contact point with $\mathrm{Si}$ in a way that the electrostatic repulsion of charged Alg and its interaction with $\beta$-CDp extends the neutral aggregated $\beta$-CDp polymer network. This result along with the previous literature ${ }^{41}$ implies that supramolecular interactions are critical not only to increase the adhesion, but also to control the morphology of the polymer networks for efficient binder-binder and binder-Si interactions. The $\beta$-CDp/Alg-Si anode achieved $70.6 \%$ capacity retention after 100 cycles.

Murase et $a l .{ }^{61}$ reported the effect of branching density of polymeric binders on electrochemical performance of Si/graphite anodes by using three crop-derived polysaccharides with varying branch numbers: amylose (linear polymer), amylopectin (moderately hyperbranched polymer), and glycogen (highly hyperbranched polymer) (Fig. 7). Among these binders, moderately hyperbranched polymer (amylopectin) showed higher specific capacity with better capacity retention in comparison with PVDF, linear amylose, and highly hyperbranched glycogen.
The unexpected inferior performance of glycogen-Si results from the thick coverage of glycogen layer on Si surface, hindering lithium-ion transport and consequently impairing the specific capacity. This result clearly suggests that there is an optimum branching density for high-performance binders in Si anodes.

\subsection{Graft polymeric binders}

A graft polymer is a branched polymer containing pendant chains. Wei et al. synthesized poly(acrylic acid sodium) grafted carboxylmethyl cellulose (NaPAA- $g$-CMC) via grafting-from method as a binder for $\mathrm{Si}$ anodes (Fig. 8). ${ }^{62}$ NaPAA- $g$-CMC-Si can form multidimensional contacts with Si surface via strong hydrogen bonding and ion-dipole interactions, leading to a stronger adhesion property of NaPAA- $g$-CMC-Si anode compared to that of linear binder-based ones, i.e., CMC-Si and NaPAA-Si. The electrochemical tests were carried out by a galvanostatic measurement with a half-cell consisting of $60 \mathrm{wt} \%$ silicon nanoparticle (diameter $=50-100 \mathrm{~nm}$, Si loading $=0.45 \mathrm{mg} \mathrm{cm}{ }^{-2}$ ), $20 \mathrm{wt} \%$ conductive agent (Super P), and $20 \mathrm{wt} \%$ binder. 


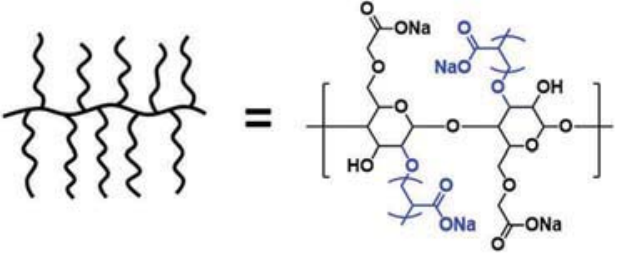

Graft Polymer
NaPAA-g-CMC

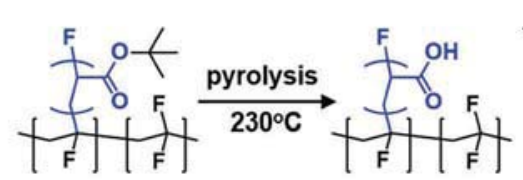

PVDF-g-PtBA

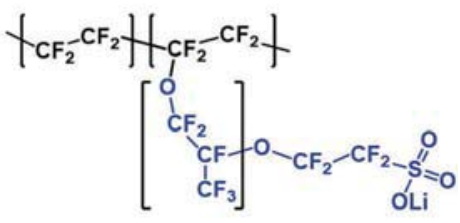

Li-Nafion

Fig. 8 Graft polymeric binders: NaPAA-g-CMC, PVDF-g-PtBA, and Li-Nafion.

NaPAA-g-CMC-Si exhibited a reversible capacity of $1816 \mathrm{~mA} \mathrm{~h} \mathrm{~g} \mathrm{~g}^{-1}$ with a capacity retention of $79.3 \%$ after 100 cycles when measured at $840 \mathrm{~mA} \mathrm{~g}^{-1}$, while CMC-Si, PAA-Si, and NaPAA-mix-CMC-Si anodes retained $39 \%, 45.5 \%$, and $43 \%$ after 100 cycles, respectively. This result points to the fact that ion-dipole interactions offer better cycling stability compared to the hydrogen bonding interactions primarily due to their higher bonding strength. We should, however, also consider in situ lithiation of hydroxyl moieties, which could improve the performance of these binders.

Lee et al. also investigated poly(vinylidene difluoride)-graftpoly(tert-butylacrylate) (PVDF- $g$-PtBA) as a graft polymeric binder (Fig. 8).$^{63}$ Upon heating the electrode at $230{ }^{\circ} \mathrm{C}$ under vacuum for overnight, PtBA of PVDF- $g$-PtBA was pyrolyzed to poly(acrylic acid) (PAA) which can form hydrogen bonds and/or covalent bonds with Si. The electrochemical performance of the Si anodes was examined using an electrode consisting of $60 \mathrm{wt} \% \mathrm{Si}$ (3D porous $\mathrm{Si}$, Si loading $=2 \mathrm{mg} \mathrm{cm}^{-2}$ ), $20 \mathrm{wt} \%$ conductive agent (Super P), and $20 \mathrm{wt} \%$ binder. As compared with PVDF, the porous Si anode combined with PVDF-g-PtBA exhibited a higher capacity of $1711 \mathrm{~mA} \mathrm{~h} \mathrm{~g}{ }^{-1}$ with a capacity retention of $84 \%$ after 50 cycles (current density $=840 \mathrm{~mA} \mathrm{~g}^{-1}$ ). The PVDF- $g$-PtBA was found to suppress the electrode swelling upon cycling due to the enhanced adhesion ability through multidimensional contacts of its graft polymer architecture. Whereas PVDF-Si showed an enormous volume change of $213 \%$ after 50 cycles, PVDF-g-PtBA(17)-Si showed only $100 \%$ expansion. The full cell of porous $\mathrm{Si} /$ natural graphite coupled with $\mathrm{LiNi}_{0.5} \mathrm{Mn}_{1.5} \mathrm{O}_{4}$ cathode delivered an energy density of $546 \mathrm{~W} \mathrm{~h} \mathrm{~kg}^{-1}$ with a capacity retention of approximately $70 \%$ after 50 cycles at a rate of $1 \mathrm{C}\left(145 \mathrm{~mA} \mathrm{~g}^{-1}\right)$.

Garsuch et al. used Nafion as a binder for Si microparticle anodes. ${ }^{64}$ Nafion is a graft polymer composed of polytetrafluoroethylene backbone with side chains of perfluoronated vinylethers terminated by sulfonic acid group (Fig. 8). They prepared lithiated Nafion (Li-Nafion) by ion exchange of $\mathrm{LiOH}$ with sulfonic acid groups. The Si anode was prepared by including $80 \mathrm{wt} \%$ Si $(\sim 325$ mesh size, diameter $=5-20 \mu \mathrm{m}$, loading $=$ $1.5-1.9 \mathrm{mg} \mathrm{cm}{ }^{-2}$ ), $12 \mathrm{wt} \%$ conductive agent (Super $\mathrm{S}$ ), and $8 \mathrm{wt} \%$ binder. When cycled at $150 \mathrm{~mA} \mathrm{~g}^{-1}$ between 0.17 and $0.9 \mathrm{~V}$ (not fully lithiated), Li-Nafion-Si anode delivered $\sim 660 \mathrm{~mA} \mathrm{~h} \mathrm{~g}^{-1}$ with a capacity retention of $70 \%$ after 100 cycles. While Li-Nafion-Si anode showed much better cycle life than that of Nafion-Si, other research ${ }^{55,65}$ for Si nanoparticle anodes showed that their performance was almost comparable or Li-Nafion-Si was slightly better.

\subsection{Network polymeric binders}

A network polymer has an interconnected architecture formed by covalent crosslinking of polymer chains or polymerizing multifunctional monomers. Network polymers with supramolecular interactions can provide an excellent scaffold to limit the movement of Si particles and generate the self-healing effect. While the less crosslinked polymers can be directly used as binders due to their solubility, highly crosslinked polymers are limited on account of their poor processability. Hence, many in situ crosslinking chemistries have been investigated to form network polymers in electrodes by heating or light irradiation.

3.3.1. Condensation reaction between $-\mathrm{COOH}$ and $-\mathrm{OH}$. The condensation reaction between carboxyl and hydroxyl groups were widely used to form network polymeric binders because many reported good binders such as CMC, PAA, and Alg inherently have these functional groups. Koo et al. developed the crosslinked poly(acrylic acid)-carboxymethyl cellulose (c-PAA-CMC) as a network polymeric binder (Fig. 9). ${ }^{66}$ The Si electrodes were prepared by containing $60 \mathrm{wt} \% \mathrm{Si}$ (diameter $<100 \mathrm{~nm}$, Si loading was not given), $20 \mathrm{wt} \%$ conductive agent (Super P), and $20 \mathrm{wt} \%$

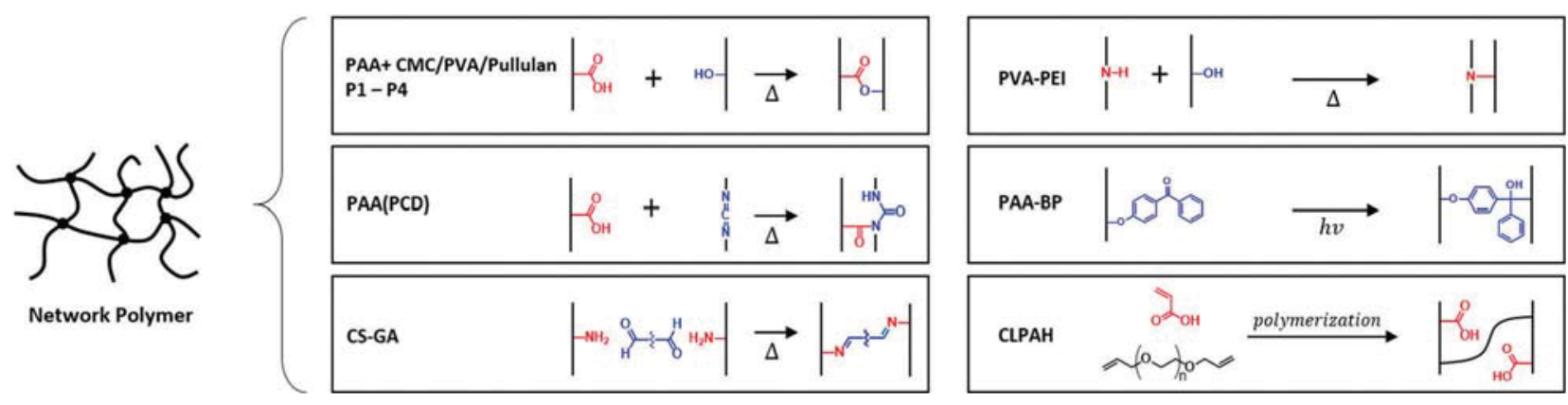

Fig. 9 Network polymers and their representative crosslinking chemistry. 
binder (PAA: $\mathrm{CMC}=10: 10 \mathrm{wt} \%)$. While drying the electrode at $150{ }^{\circ} \mathrm{C}$ under vacuum, the condensation reaction between carboxylic acid moieties of PAA and hydroxyl groups of CMC took place to form ester linkages. The resulting three-dimensionally crosslinked c-PAA-CMC was effective in suppressing the deformation of the electrode as confirmed by the smaller change in electrode thickness (35\% in the fully lithiated state) while the PVDF led to $130 \%$ volume change. Beyond the positive effect of the crosslinked configuration of the polymer network, remaining hydroxyl and carboxyl groups are expected to form strong supramolecular interactions with $\mathrm{Si}$. These synergistic effects enable the c-PAA-CMC-Si anode to deliver approximately $2140 \mathrm{~mA} \mathrm{~h} \mathrm{~g}^{-1}$ with a good capacity retention of $\sim 75 \%$ after 100 cycles at a current density of $300 \mathrm{~mA} \mathrm{~g}^{-1}$.

Song et al. demonstrated that crosslinked poly(acrylic acid) (PAA) and polyvinyl alcohol (PVA) (PAA-PVA) showed enhanced cycle life due to improved mechanical adhesion in comparison to linear polymers susceptible to slipping upon the continuous volume change of Si during cycling (Fig. 9) ${ }^{67}$ They prepared the electrodes consisting of $60 \mathrm{wt} \% \mathrm{Si}$ nanoparticle (diameter <

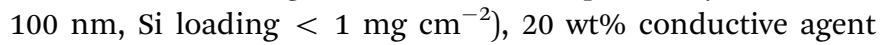
(Super P), and $20 \mathrm{wt} \%$ binder (PAA : PVA = 90:10 wt\%). During a drying step at $150{ }^{\circ} \mathrm{C}$, carboxyl moieties of PAA react with hydroxyl groups of PVA to form a crosslinked polymer network. The PAA/PVA-Si anode exhibited a gravimetric capacity of $2283 \mathrm{~mA} \mathrm{~h} \mathrm{~g}^{-1}$ with $63 \%$ capacity retention after 100 cycles at a current density of $400 \mathrm{~mA} \mathrm{~g}^{-1}$, which was higher than that of CMC-Si (1178 mA h g ${ }^{-1}$, capacity retention: $35.9 \%$ after 100 cycles) and PVDF-Si (180 $\mathrm{mA} \mathrm{h} \mathrm{g}^{-1}$ after 100 cycles).

Hwang et al. used PAA and pullulan to form a crosslinked polymeric binder (PAA/pullulan) (Fig. 9). ${ }^{32}$ In the same way as above, carboxylic acid units of PAA underwent a condensation reaction with hydroxyl groups of pullulan upon heating the electrode at $150{ }^{\circ} \mathrm{C}$ under vacuum. Pullulan is distinguished from other stiff polysaccharides containing $\beta$-glycosidic linkage such as alginate and CMC in that pullulan composed of $\alpha-(1 \rightarrow 6)$-linked maltotriose units can change its conformation from chair to boat in PAA/pullulan, thus rendering PAA/pullulan highly flexible. Due to this flexibility, the thickness change of PAA/pullulan-Si electrode was higher than that of crosslinked PAA/CMC-Si electrode. Nevertheless, the mechanical stability of PAA/pullulan-Si anode was much better as demonstrated by macroscopic folding test of electrodes and SEM analyses. For electrochemical measurements, $\mathrm{Si}$ electrodes were fabricated by containing $60 \mathrm{wt} \% \mathrm{Si}$ (diameter $=100 \mathrm{~nm}$, Si loading was not given), $20 \mathrm{wt} \%$ conducting agent (Super P), and $20 \mathrm{wt} \%$ binder (PAA: pullulan $=10: 10 \mathrm{wt} \%)$. The capacity of PAA/pullulan-Si anode after 200 cycles was approximately $78 \%$ of initial capacity when lithiated at $840 \mathrm{~mA} \mathrm{~g}^{-1}$ and delithiated at $2100 \mathrm{~mA} \mathrm{~g}^{-1}$, while both PAA/CMC-Si and PAA-Si anodes failed before 150 cycles.

Jeena et al. synthesized poly(acrylic acid-co-vinyl alcohol) with varying ratio of monomers $(\mathrm{P} 1, \mathrm{P} 2, \mathrm{P} 3, \mathrm{P} 4$ with PAA: $\mathrm{PVA}=$ $33: 67,60: 40,71: 29,75: 25$, respectively) (Fig. 9). ${ }^{68}$ Si electrodes were prepared by containing $60 \mathrm{wt} \% \mathrm{Si}$ (diameter $=100 \mathrm{~nm}$, Si loading was not given), $20 \mathrm{wt} \%$ conductive agent (Super P), and $20 \mathrm{wt} \%$ binder. While drying the electrodes at $150{ }^{\circ} \mathrm{C}$ under vacuum, the binders $\mathrm{P} 1-\mathrm{P} 4$ underwent a condensation reaction between $-\mathrm{COOH}$ of PAA and -OH of PVA, forming threedimensional crosslinked polymer networks. In these $\mathrm{P}$ series polymers, PAA increases the adhesion ability while PVA endows flexibility. Among P1-P4, P2 showed the best cycling performance, which indicates that the optimum balance of PAA and PVA is required to keep the mechanical integrity of Si anodes. Also, the P2-Si anode showed the good rate performance at $20 \mathrm{~A} \mathrm{~g}^{-1}$ as compared with linear polymers such as PVDF, PVA, PAA, and mixture of PVA/PAA.

3.3.2. Carbodiimide chemistry between - $\mathrm{COOH}$ and $-\mathbf{N}=\mathbf{C}=\mathbf{N}-$. Han et al. adopted the carbodiimide crosslinking chemistry to covalently crosslink PAA binders by using polycarbodiimide (PCD) as a crosslinker (Fig. 9).${ }^{69}$ They mixed various amounts of PCD with PAA in slurry, in which carboxylic acids of PAA reacted with carbodiimides of PCD to afford the network polymeric binder $\mathrm{PAA}_{x}(\mathrm{PCD})_{y}$ through $N$-acylurea linkage. Among $\mathrm{PAA}_{x}(\mathrm{PCD})_{y}$ where $x$ and $y$ are the weight percentage of PAA and PCD in the electrode, $\mathrm{PAA}_{9}(\mathrm{PCD})_{1}-\mathrm{Si} /$ graphite anode showed the most uniform electrode morphology and the best cycling performance with a capacity retention of $75 \%$ after 30 cycles. The comparative analysis indicates that the lower crosslinking (below $1 \mathrm{wt} \%$ of PCD) leads to less stable electrode whereas the higher crosslinking (above $1 \mathrm{wt} \%$ of PCD) decreases the supramolecular interactions by consuming carboxylic acids of PAA. These results further point to the delicate balance between covalent crosslinking and the availability of functional groups for supramolecular interactions.

3.3.3. Schiff base reaction between $-\mathrm{NH}_{2}$ and $-\mathrm{CHO}$. Chen et al. crosslinked chitosan (CS) binder by using various amounts of glutaraldehyde (GA) as a crosslinker, yielding crosslinked chitosan polymers $\left(\mathrm{CS}-\mathrm{GA}_{x}\right.$ where $x$ is the weight\% of $\mathrm{GA}$ ) (Fig. 9) ${ }^{70}$ While drying the cast slurry at $80{ }^{\circ} \mathrm{C}$, amine groups of CS reacted with aldehydes of CS to form imine linkages. This report is certainly an interesting application of dynamic covalent chemistry, which could introduce reversibility to the resulting binder network. With the increase in the amount of GA crosslinker, the electrolyte uptake and the swelling of CS-GA films decreased because the highly crosslinked polymer prevents the electrolyte from infiltrating into the film due to its dense network conformation. This property is suitable for maintaining the adhesion strength in the binder-binder and binder-Si interactions. The Si electrodes were prepared by containing $60 \mathrm{wt} \%$ Si (diameter $=100 \mathrm{~nm}$, Si loading was not given), $20 \mathrm{wt} \%$ conductive agent (Super P), and $20 \mathrm{wt} \%$ binder. With the increase in the amount of GA crosslinker until CS-GA3, the capacity retention of CS-GA-Si anodes was improved due to the effect of branched structure. However, CS-GA5-Si anode showed rather decreased performance compared to that of CS-GA3-Si anode, which indicates that strong supramolecular interactions are also necessary for the long-term stabilization by the self-healing effect. These results equally indicate that blindly increasing crosslinking density is not the right direction to stabilize $\mathrm{Si}$ anodes.

3.3.4. Condensation reaction between $-\mathrm{NH}_{2}$ and $-\mathrm{OH}$. Liu et al. covalently crosslinked poly(ethylene imine) (PEI) (20 w\%) 
and poly(vinyl alcohol) (PVA) (80 wt\%) by in situ thermal condensation reaction between amine groups of PEI and hydroxyl groups of PVA during a drying step at $100-120{ }^{\circ} \mathrm{C}$ (Fig. 9). ${ }^{71}$ The electrochemical performance of PVA/PEI-Si anodes was examined by using a coin-type half-cell containing $60 \mathrm{wt} \% \mathrm{Si}$ $\left(\right.$ diameter $=50 \mathrm{~nm}$, Si loading $=1.8-2.7 \mathrm{mg} \mathrm{cm} \mathrm{cm}^{-2}$ ), $20 \mathrm{wt} \%$ conductive agent (Super P), and $20 \mathrm{wt} \%$ binder. PVA/PEI-Si anode maintained its reversible capacity of $1060 \mathrm{~mA} \mathrm{~h} \mathrm{~g}^{-1}$ with capacity retention of $34.5 \%$ after 300 cycles, which was higher than that of $\mathrm{Si}$ anodes with linear binder CMC and PVDF. Nonetheless, the observed capacity retention of PVA-PEI-Si needs to be improved further for competition with other available binders.

3.3.5. Photo-cross-linkable polymeric binders. Park et al. reported the photo-crosslinkable poly(acrylic acid) (PAA-BP) polymer incorporating a photoreactive benzophenone (BP) group (Fig. 9). ${ }^{72}$ Upon UV irradiation (365 nm), the benzophenone moiety generates a biradical species that can abstract hydrogen from carboxylic acid moieties of PAA to form a C-C bond. For the electrochemical performance, the $\mathrm{Si}$ anodes were prepared by containing carbon-coated Si (diameter $<100 \mathrm{~nm}$, Si loading was not given), conductive agent (Super P), and binder in a weight ratio 8:2:1 (Si:Super P: binder). After that, the photocrosslinking reaction was carried out via the exposure of the electrodes to UV light. The crosslinked PAA-BP-Si anode substantially improved the capacity retention over 100 cycles as compared with the bare PAA-BP-Si anode that did not undergo the UV irradiation. Besides, the crosslinked PAA-BP-Si electrode showed a good rate performance of $1420 \mathrm{~mA} \mathrm{~h} \mathrm{~g}^{-1}$ at $20 \mathrm{~A} \mathrm{~g}^{-1}$, while the specific capacity of the bare PAA-BP-Si electrode was around $700 \mathrm{~mA} \mathrm{~h} \mathrm{~g}^{-1}$ at the same current density. This outstanding electrochemical performance reflects that the covalently crosslinked PAA-BP can limit the deformation of the Si anodes, resulting in a smaller change in the electrode thickness. It is also important to recognize that this approach may not work as effectively for thicker electrodes due to the limited penetration of light.

3.3.6. Polymerization. Crosslinked polymers can also be directly obtained from multifunctional monomers. Aoki et al. polymerized the crosslinked acrylic acid-based copolymer $(x \mathrm{CLPAH})$ by using acrylic acid with various amounts $(x=0,1$, 10, 20, and 100) of diallyl ethers as a crosslinker (Fig. 9). ${ }^{73}$ The effect of these binders was examined by preparing the Si/graphite anodes consisting of $30 \mathrm{wt} \% \mathrm{Si}$ (diameter $<100 \mathrm{~nm}$ ), $50 \mathrm{wt} \%$ graphite (particle size $=3 \mu \mathrm{m}$ ), $10 \mathrm{wt} \%$ conducting agent (acetylene black), and $10 \mathrm{wt} \%$ binder. Among the series of $x \mathrm{CLPAH}$, the moderately crosslinked polymer, 10CLPAH, attained the best capacity retention due to the enhanced mechanical durability along with strong supramolecular interactions originating from the remaining carboxylic acid moieties. When the neutralized polymers $\left(20 \mathrm{CLPAH}_{0.2} \mathrm{Na}_{0.8}\right)$ were used as a binder, the corresponding $\mathrm{Si}$ anode exhibited improved performance with regard to the stability of SEI layer and the cyclability. This is likely due to the increased ion-dipole interactions and stretched polymer morphology from electrostatic repulsion of negatively-charged carboxylates.

Lopez et al. ${ }^{74}$ investigated the crosslinking effect of the ureabased self-healing binder (SHP) previously developed by Chen et $a .^{30}$ They synthesized SHP with different crosslinking densities by varying the amount of triacid from 16 to $70 \%$. The Si anodes were prepared by including $55.7 \mathrm{wt} \% \mathrm{Si}$ (diameter $=800 \mathrm{~nm}, \mathrm{Si}$ loading $=0.75-1.1 \mathrm{mg} \mathrm{cm}^{-2}$ ), $5.8 \mathrm{wt} \%$ conductive agent (carbon black), and $38.5 \mathrm{wt} \%$ binder. Interestingly, $70 \%$ trifunctional SHP-Si anode exhibited the strongest adhesion among all electrodes tested, but moderately crosslinked SHP (30-57\% triacid) delivered the best cycling performance. This result suggests that the adhesion strength evaluated by peeling test or simple tape test is not necessarily translated to the good electrochemical performance of Si anodes. The self-healing efficiency along with the adhesion strength must be considered at the same time.

\subsection{Polymer networks formed by noncovalent/dynamic crosslinking}

Noncovalent/dynamic crosslinking of polymers and/or polymer networks with strong supramolecular interactions is a good strategy to realize the synergistic effect of self-healing and adhesion strength. Along this direction, supramolecular crosslinking can be exploited to form branched polymers. Additionally, their crosslinking process is spontaneous and reversible, and therefore the functional groups are not consumed as opposed to covalent crosslinking. Towards this end, several interesting approaches have been reported using double helix formation, host-guest interactions, and ionic bonds.

3.4.1. Double helix formation. Jeong et al. ${ }^{75}$ demonstrated that the helical structure of native xanthan gum (native-XG) leads to the formation of an interconnected polymer network, which enhances its adhesion ability and consequently electrochemical performance for $\mathrm{Si}$ anodes. The native-XG has a linear backbone of polysaccharide composed of (1,4)- $\beta$-D-glucose unit with trisaccharide side groups containing two negative carboxylates (Fig. 10). The balance

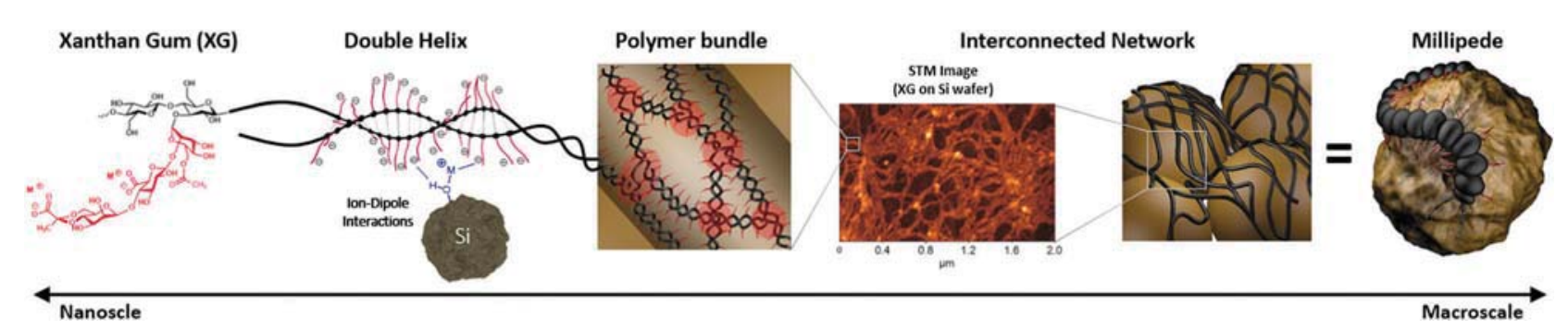

Fig. 10 Structural characteristics of xanthan gum from nanoscale to macroscale. Adapted from ref. 75 with permission from The Royal Society of Chemistry, copyright 2015. 
between attractive force of the intra/intermolecular hydrogen bonding of the backbones and electrostatic repulsion of side groups leads to the formation of a double helical structure. The resultant double helices can be connected end-to-end, constituting polymer bundles and interconnected network as visualized by the scanning probe microscopy (SPM) in Fig. 10. The side chains sticking out from the helices can form strong iondipole interactions with Si surface, resulting in strong adhesion properties. This excellent adhesion property of native-XG was observed in crack-free electrode morphology. The cell performance was investigated using galvanostatic measurement of Si anodes consisting of $60 \mathrm{wt} \% \mathrm{Si}$ (diameter $=60 \mathrm{~nm}$, Si loading $=$ $0.3 \mathrm{mg} \mathrm{cm}^{-2}$ ), $20 \mathrm{wt} \%$ conductive agent (Super P), and $20 \mathrm{wt} \%$ binder. In comparison to other polysaccharide binders (cellulose, amylose, amylopectin, CMC, and Alg), native-XG-Si anode exhibited the best electrochemical performance with a large specific capacity ( $2150 \mathrm{~mA} \mathrm{~h} \mathrm{~g}^{-1}$ at the 200th cycle), a good capacity retention $(72.2 \%$ after 200 cycles), and decent rate capability at $21 \mathrm{~A} \mathrm{~g}^{-1}$. The native-XG also operated well in the Si/graphite anodes (Si : graphite $=20: 80 \mathrm{wt} \%$ ).

Similarly, Klamor et al. ${ }^{76}$ used gellan gum as a binder for $\mathrm{Si} /$ graphite anodes (20:60 wt\%). Although they did not emphasize the double helix structure of the gellan gum, it is well known that gellan gum forms a left-handed helical structure just like xanthan gum. ${ }^{77}$ Instead, they attributed the high performance of gellan gum-Si/graphite anode to the high density of polar functional groups of gellan gum that enables a more efficient coverage and interaction with Si particles. While CMC-Si/graphite anode showed a sudden capacity drop and continuous fading at $60{ }^{\circ} \mathrm{C}$, gellan gum-Si/graphite anode showed enhanced cycling stability. These results clearly reflect the importance of polymer superstructure originating from supramolecular interactions between individual polymer chains and the chemical structures of the polymer on the resulting electrochemical performance.

3.4.2. Host-guest interactions. Kwon et al. $^{78}$ introduced the concept of dynamic crosslinking based on the host-guest interactions to form an interconnected polymeric binder network (Fig. 11). Among many host-guest pairs, they chose $\beta$-cyclodextrin $(\beta-\mathrm{CD})$ and adamantane $(\mathrm{AD})$ because their association force is known to be strong to crosslink $\beta$-CD polymer ( $\beta$-CDp) and quite reversible. ${ }^{79}$ By using these features, they demonstrated that $\beta$-CDp binder can be strongly crosslinked in $\mathrm{Si}$ anodes by using a dendritic crosslinker incorporating 6 adamantane units (6AD), and this crosslinking is self-healable while the corresponding $\mathrm{Si}$ anode undergoes the volume change. Electrochemical measurement was performed by fabricating $\mathrm{Si}$ anodes consisting of $60 \mathrm{wt} \% \mathrm{Si}$ (diameter $=50 \mathrm{~nm}$, Si loading $=0.8 \mathrm{mg} \mathrm{cm}^{-2}$ ), $20 \mathrm{wt} \%$ conductive agent (Super P), and $20 \mathrm{wt} \%$ binder with varying amounts of 6AD. They tested all combinations of binder $(\alpha, \beta$, and $\gamma$-CDp) and crosslinker (6AD and 1AD). Among these electrodes, $\beta$-CDp/6AD-Si anode exhibited the best cycling performance because of the size compatibility between host and guest as well as the sufficient length of the crosslinker to facilitate the dynamic crosslinking.

3.4.3. Ionic crosslinking. It is well-known that the two sequential guluronic acid blocks (GG) of alginate strongly capture divalent cations such as $\mathrm{Ca}^{2+}$ via the egg-box mechanism (Fig. 12A). Liu et al. ${ }^{80}$ applied the calcium-mediated crosslinked alginate (Alg-Ca) as a binder for carbon-coated $\mathrm{Si}$ anodes ( $\mathrm{Si}:$ carbon $=80: 20 \mathrm{wt} \%)$. They prepared the $\mathrm{Si} / \mathrm{C}$ anodes that consist of $53 \mathrm{wt} \% \mathrm{Si} / \mathrm{C}, 18 \mathrm{wt} \%$ conductive agent (carbon black), and $29 \mathrm{wt} \%$ binder. Alg-Ca was prepared by adding $1 \mathrm{wt} \% \mathrm{CaCl}_{2}$ aqueous solution to the aqueous Alg solution. The Alg-Ca-Si anode showed improved cycling performance $\left(1822 \mathrm{~mA} \mathrm{~h} \mathrm{~g}{ }^{-1}\right.$ with a capacity retention of $82.3 \%$ after 120 cycles) than that of $\mathrm{Alg}-\mathrm{Si}$ anode due to the enhanced mechanical property facilitated by $\mathrm{Ca}^{2+}$-mediated ionic crosslinking.

Zhang et al. ${ }^{81}$ investigated the effect of crosslinking density of Alg-Ca on the electrochemical performance for Si anodes by varying the molar fraction between $\mathrm{Ca}^{2+}$ and Alg residue from 0 to 0.15 . They prepared Si electrodes including $70 \mathrm{wt} \% \mathrm{Si}$ $\left(\right.$ diameter $=\sim 200 \mathrm{~nm}$, Si loading was $\left.1.0-1.1 \mathrm{mg} \mathrm{cm}^{-2}\right), 15 \mathrm{wt} \%$ conductive agent (Super P), and $15 \mathrm{wt} \%$ binder. With increasing $\mathrm{CaCl}_{2}$, the peeling force of Alg-Ca-Si anodes increased, implying that strong adhesion was achieved by ionic crosslinking. Due to this strong adhesion property, Alg-Ca-0.15-Si anode exhibited the highest specific capacity of $2837.5 \mathrm{~mA} \mathrm{~h} \mathrm{~g}^{-1}$ with a high capacity retention of $86.2 \%$ after 200 cycles among all Alg-Ca-Si anodes. However, the Alg-Ca-0.15 showed a lower initial Coulombic efficiency of $80.2 \%$ compared to those of Alg-Ca-0 (86.1\%), Alg-Ca-;0.05 (85.9\%), and Alg-Ca-0.1 (83.2\%).

Yoon et al. $^{82}$ also investigated $\mathrm{Alg}-\mathrm{Ca}$ as a binder for $\mathrm{Si}$ anodes with more emphasis on mechanical properties of ionic crosslinking. They carried out a tensile test for various
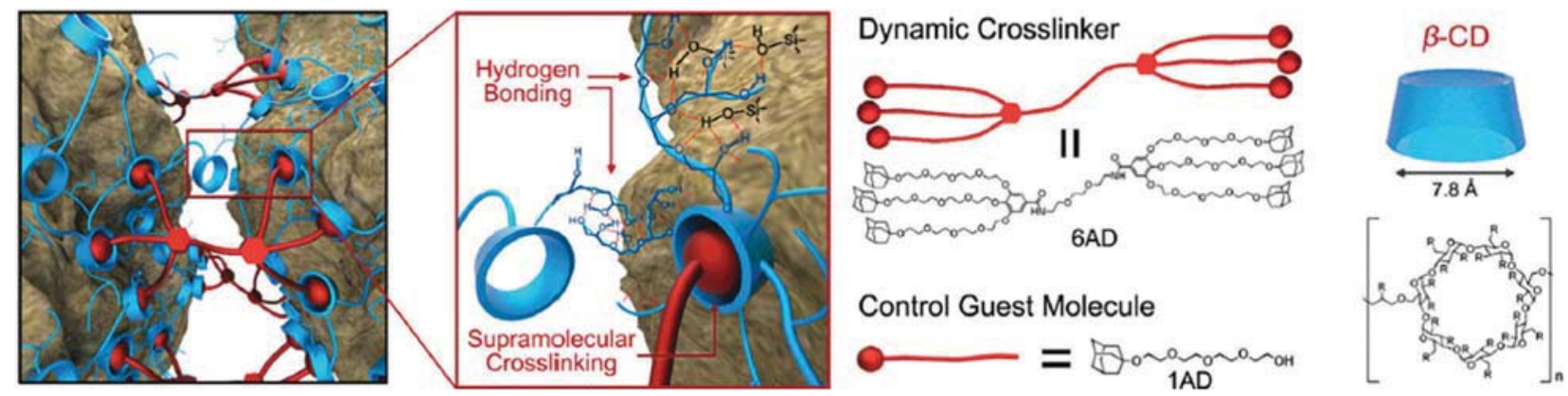

Fig. 11 Dynamic crosslinking base on the host-guest interaction between $\beta$-CD and 6AD. Adapted with permission from ref. 78 . Copyright 2015 American Chemical Society. 
(A)
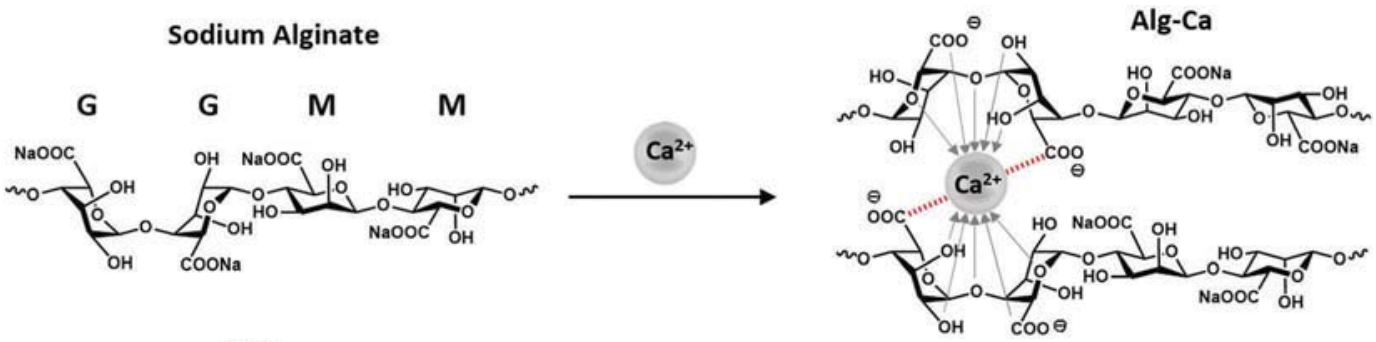

(B)
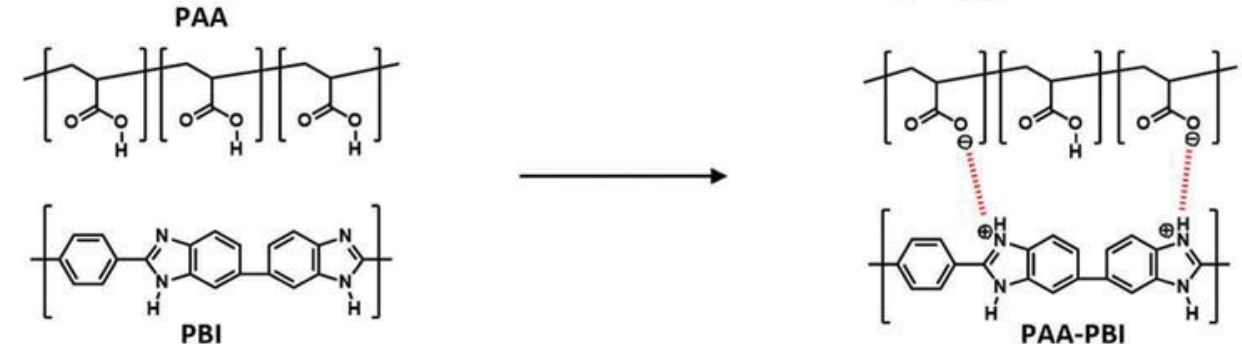

Fig. 12 lonic crosslinking of polymeric binders.

polymer films; Alg-Ca showed much higher toughness (13.5 $\mathrm{MJ} \mathrm{m}^{-3}$ ) and stiffness (510 MPa) than those of Alg-Na $\left(4.8 \mathrm{MJ} \mathrm{m}^{-3}, 121 \mathrm{MPa}\right)$. Given the fact that a control experiment of Alg-Ca treated with ethylenediaminetetraacetic acid (EDTA, calcium capture) showed toughness of $3.3 \mathrm{MJ} \mathrm{m}^{-3}$ and stiffness of $132 \mathrm{MPa}$, the enhanced properties in those mechanical parameters are ascribed to the ionic crosslinking. Alg-Ca also showed better strain recovery of $\sim 65 \%$ after 20 stretchrelease cycles at $5 \%$ loading strain than Alg-Na and Alg-Ca with EDTA treatment; both Alg-Na and Alg-Ca with EDTA treatment were broken before 3 cycles. Also, the mechanical properties of Alg-Ca are not expected to vary much after the uptake of electrolyte because Alg-Ca absorbs less electrolyte $(\sim 4.2 \%)$ than Alg-Na $(\sim 8.7 \%)$, PVDF $(\sim 165 \%)$, and CMC $(\sim 8.8 \%)$. Owing to these improved mechanical properties, $\mathrm{Si}$ anode with Alg-Ca achieved a good capacity retention (83\% after 300 cycles), rate capability (1029 $\mathrm{mA} \mathrm{h} \mathrm{g}^{-1}$ at $2000 \mathrm{~mA} \mathrm{~g}^{-1}$ ), and thermal stability. The challenge for these particular studies, however, is to achieve good dispersion of electrode components considering the extremely fast gelation kinetics of Alg and metal ions.

Lim et $a l .{ }^{83}$ utilized the reversible acid-base interaction for the ionic crosslinking of polymeric binders for $\mathrm{Si} /$ graphite anodes. As displayed in Fig. 12B, protons are moved from carboxylic acids of poly(acrylic acid) (PAA) to nitrogen atoms of poly(benzimidazole) (PBI) via acid-base reaction, which forms complementary imidazolium carboxylate pairs. PAA and PBI are crosslinked via the ion-ion interactions between imidazolium and carboxylate moieties, resulting in robust mechanical properties and consequently enhanced battery performance. $\mathrm{Si} /$ graphite anodes were prepared by containing $80 \mathrm{wt} \%$ $\mathrm{Si} /$ graphite (30:70 wt\%), $10 \mathrm{wt} \%$ conductive agent (Super P), and $10 \mathrm{wt} \%$ binder (PAA, PAA-PBI-2, PAA-PBI-5 where the number indicates the weight $\%$ of $\mathrm{PBI}$ ). Among these binders, PAA-PBI-2-Si anode showed the highest Coulombic efficiency (initial $=87.5 \%$, average $=99.1 \%$ over 100 cycles) and the highest capacity retention due to the low polarization, reversible bonding, and strong adhesion with Si.

\section{Conductive polymeric binders}

Inherently low conductivity of Si necessitates the addition of conductive agent in the electrode. However, it has been proposed that such effect can also be realized by using conductive polymers that serve as both binders and conductive agents. In this scenario, as the contents of conductive agents can be lowered substantially, the loading of active material ( $\mathrm{Si}$ ) can be further increased, thus enhancing the specific energy density of the corresponding cell. Along this direction, it is desired to decrease the amount of inactive components as they do not contribute to the electrochemical capacity. In addition, the thick binder layer can also hinder the transport of lithium ions and electrons, thus increasing the polarization of the electrode.

Conductive polymeric binders are promising candidates in overcoming the drawbacks associated with the use of Si owing to the improved electrical integrity of the electrode (Fig. 13). When widely adopted carbon powder is used as a conductive agent, it becomes apart from Si particles during the repeated volume change of $\mathrm{Si}$ (Fig. 13A), interrupting electron flow throughout the electrode. Basically, the non-adhesive conductive agents are susceptible to disconnection from Si particles, leading to rapid capacity fading (Fig. 13A). In contrast, it is envisaged that conductive binder can remain as a conducting bridge between $\mathrm{Si}$ particles as long as the binder adheres to $\mathrm{Si}$ particles, keeping Si electrochemically active (Fig. 13B). This strategy, however, can only be effective if the conductive binder presents both the strong interaction with $\mathrm{Si}$ and high electric conductivity. While this section focuses more on the electric conductivity, it should be noted that even a highly conductive binder cannot sustain stable cycling without strong adhesion ability. $^{84-86}$ 
(A) Conventional conductive agent

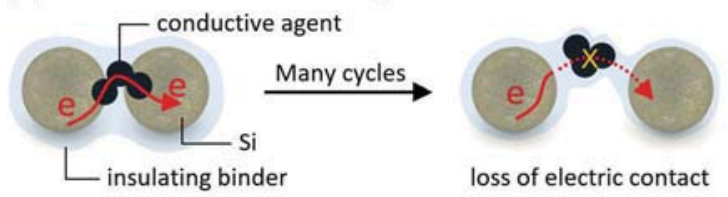

(B) Conductive binders

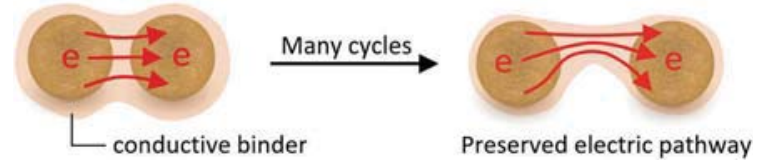

Fig. 13 Working principles of (A) conventional Si electrodes using conductive agents and (B) Si electrodes using conductive binders.

Conductive polymers are organic polymers with extended $\pi$-conjugation throughout the polymer backbone, which enables efficient transport of electrons. In order to endow conjugated polymers with high electrical conductivity, they need to be doped by either oxidation (p-doping) or reduction (n-doping). During p-doping, some of the delocalized electrons are removed, and positive polarons/bipolarons are generated. ${ }^{87}$ The electrons within the resultant partially empty energy level have high mobility. In the case of n-doped polymers, electrons are injected to the polymer backbone, thus generating negative polarons/bipolarons with high mobility. ${ }^{87}$ Therefore, the doping process is essential to have improved conductivity.

\subsection{P-Type binders without doping}

Si anodes are charged under reducing conditions with an operating voltage in the range of $0-1.5 \mathrm{~V}$ versus $\mathrm{Li} / \mathrm{Li}^{+}$. Whereas n-type polymers can be electrochemically doped in this voltage range, p-type polymers cannot. Indeed, several literature reports on p-type binders for $\mathrm{Si}$ anodes such as polyaniline, ${ }^{88}$ polypyrrole, ${ }^{89,90}$ and PEDOT:PSS ${ }^{91,92}$ exhibited poor cycling performances in comparison to that of the conventional Si electrodes with conductive carbon agents. Therefore, p-type binders are not generally desirable for Si anodes.

\subsection{Electrochemically $n$-doped conductive binders}

n-Type polymers could be suitable candidates as conductive binders for Si anodes due to the fact that they can be doped within the operating voltage range of $\mathrm{Si}$ anodes. Unfortunately, there are much less commercialized n-type conductive polymers compared to the p-type counterparts, which is probably associated with their limited air stability. For well-fitted n-type conductive binders for $\mathrm{Si}$ anodes, it is necessary to precisely tailor the energy level of the lowest unoccupied molecular orbital (LUMO) of the polymers. Electron-poor polymers can be stably $\mathrm{n}$-doped because they stabilize the negative charge and their low LUMO level facilitates the reduction of the polymers. As such, introducing electron withdrawing group into conjugated system lowers the LUMO level, which facilitates n-doping.

Liu et $a l .{ }^{84}$ developed n-type conductive binders based on polyfluorene (PF) and lowered the LUMO energy level by introducing fluorenone monomer containing electron withdrawing carbonyl groups to facilitate n-doping (Fig. 14A). X-ray absorption spectroscopy (XAS) revealed that the polymers (PFFO and PFFOMB) consisting of fluorenone have a new electronic state at $284.7 \mathrm{eV}$, which is lower than the LUMO $(285.36 \mathrm{eV})$ of PF (Fig. 14B). In contrast, p-type polyaniline (PAN) showed much higher LUMO level, thus implying that n-doping of PAN is not favourable. The cyclic voltammetry (CV) and impedance measurements validated that PFFOMB is n-doped at 1.25 and $0.5 \mathrm{~V}\left(\mathrm{Li} / \mathrm{Li}^{+}\right)$and its resistivity significantly decreased at $1.0 \mathrm{~V}$ $\left(\mathrm{Li} / \mathrm{Li}^{+}\right)$. In addition, the authors also calculated the lithium binding energy of PFFO by density functional theory (DFT) calculations. The binding energies turned out be 2.46, 2.42, 2.0, and $1.0 \mathrm{eV}$ for $\mathrm{Li}+\mathrm{PFFO}, \mathrm{Li}+\mathrm{Si}, \mathrm{Li}+\mathrm{Li}$, and $\mathrm{Li}+\mathrm{PAN}$, respectively, elucidating that $\mathrm{Li}$ ion will first react with the carbonyl group of PFFO (n-doping) before the lithiation of Si. In the same line, PAN, which is a p-type polymer, cannot be doped because the lithium binding energy $(1 \mathrm{eV})$ is much lower than that $(2.0 \mathrm{eV})$ of lithium plating. The electrochemical performances of the conducting binders are found to be in a good agreement with the trend of electric conductivity (Fig. 14C). In this study, the Si electrodes were prepared by mixing $66.7 \mathrm{wt} \%$ $\mathrm{Si}$ (diameter $<100 \mathrm{~nm}$, Si loading amount is not given) and
(A)

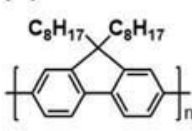

PF

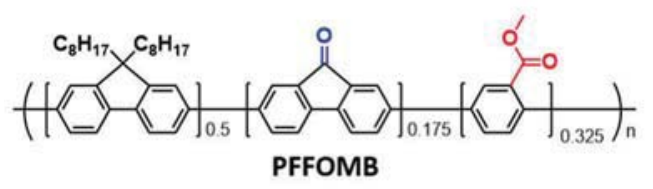

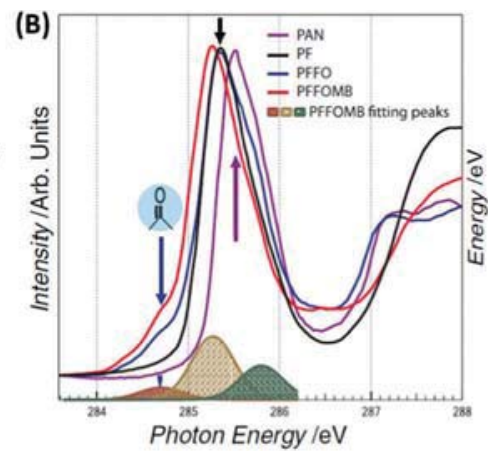

Fig. 14 (A) Chemical structures of conductive binders: PF, PFFO, and PFFOMB. Carbonyl groups in PFFO and PFFOMB reduce the LUMO level. Polar methyl carboxylate groups in PFFOMB increase the interaction with Si surface. (B) Carbon-1s XPS spectra of PFFO and PFFOMB exhibited a new energy level at $284.7 \mathrm{eV}$ originating from the carbonyl group. (C) Cycling performance of Si electrodes at a current density of $420 \mathrm{~mA} \mathrm{~g}^{-1}$. Adapted from ref. 84 with permission from Wiley-VCH Verlag GmbH \& Co., copyright 2011. 
$33.3 \mathrm{wt} \%$ binder without conductive agent. Si/PVDF showed a fast capacity decay as the electrons cannot reach Si particles due to the insulating nature of PVDF. Si/PAN showed very low initial capacity $\left(<1000 \mathrm{~mA} \mathrm{~h} \mathrm{~g}^{-1}\right)$ and rapid capacity fading due to the poor conductivity of PAN. Si/PFFO displayed much higher capacity of approximately $2900 \mathrm{~mA} \mathrm{~h} \mathrm{~g}^{-1}$ at the 1 st cycle, which is attributed to the improved conductivity of PFFO. However, the capacity decayed rapidly afterwards, and eventually the capacity retention became worse than that of Si/PVDF/acetylene black. This result represents that high conductivity alone cannot ensure good cycling performance of Si anodes. Interestingly, when the polar monomer (methyl benzoate) was introduced into the binder, that is, PFFOMB, the cycling stability was markedly enhanced. The specific capacity of Si/PFFOMB was $2100 \mathrm{~mA} \mathrm{~h} \mathrm{~g}^{-1}$ after 650 cycles. Considering that the electronic structures of PFFOMB and PFFO are not largely different, the considerable improvement results from the stronger interaction between PFFOMB and Si, revealing that the binders for $\mathrm{Si}$ anodes must have strong supramolecular interactions with the Si surface.

Similar conductive binders based on polyfluorene were subsequently reported by introducing other side chains such as triethyleneoxide monomethylester for better electrolyte uptake capability ${ }^{93}$ and sodium carboxylic acid for stronger interactions ${ }^{94}$ by forming noncovalent bonding between conductive binder and $\mathrm{Si}$ surface ${ }^{95}$ and also using calendaring technique. ${ }^{96}$ Kim et al. ${ }^{97}$ developed n-type poly(phenanthrenequinone) as a conductive binder for Si electrode. Due to the presence of two electron withdrawing carbonyl groups in phenanthrenequinone, its n-doping voltage was $0.15-0.18 \mathrm{~V}$, which is lower than that $\left(0.5 \mathrm{~V}\right.$ versus $\left.\mathrm{Li} / \mathrm{Li}^{+}\right)$of polyfluorenonebased polymers. ${ }^{84}$ Salem et al. ${ }^{98}$ investigated polythiophenes functionalized with different lengths of alkyl carboxylate as conductive binders for Si electrodes, but the specific capacity of Si/PT-3-LiA without conductive agent dropped rapidly to zero at the 30th cycle due to its low conductivity even after electrochemical n-doping, which indicates that the doping of a conductive binder does not necessarily warrant sufficient conductivity for stable cycling of Si anodes.

\subsection{Chemically p-doped conductive binders}

Wu et $a l .{ }^{85}$ chemically pre-doped p-type polyaniline (PANi) using phytic acid and used it as a conductive binder for $\mathrm{Si}$ anodes. Phosphoric acid groups in the phytic acid can form strong hydrogen bonding interactions with $\mathrm{SiO}_{2}$ layer on the $\mathrm{Si}$ surface, thus increasing the interaction between $\mathrm{Si}$ and binder. The doped state of PANi was found to be stable between 0.01-1.0 V $\left(\mathrm{Li} / \mathrm{Li}^{+}\right)$as shown in the CV analysis of the doped PANi, wherein there were no distinct redox current peaks. The electrodes were composed of $75 \mathrm{wt} \% \mathrm{Si}$ ( $\mathrm{Si}$ diameter $=60 \mathrm{~nm}$, Si loading $=$ $0.2-0.3 \mathrm{mg} \mathrm{cm}^{-2}$ ) and $25 \mathrm{wt} \%$ binder. Si/PANi electrode showed higher capacity than that of $\mathrm{Si} / \mathrm{PVDF}$ when cycled at a charge/ discharge current of $1000 \mathrm{~mA} \mathrm{~g}^{-1}$, but the capacity fading was severe (Fig. 15). Interestingly, when PANi was in situ polymerized with Si particles, the specific capacity and cycling stability was greatly improved. After 1000 cycles with a current density

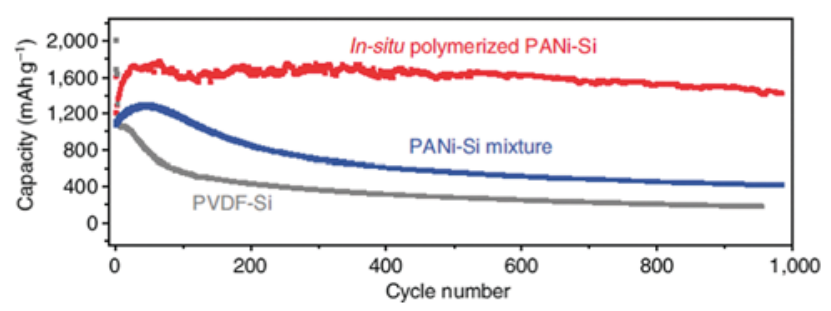

Fig. 15 Cycling performances of PVDF-Si, PANi-Si mixture, and in situ polymerized PANi-Si. The charge and discharge current density is $1000 \mathrm{~mA} \mathrm{~g}^{-1}$. Reprinted from ref. 85 with permission from Nature Publishing Group, copyright 2013.

of $1.0 \mathrm{~A} \mathrm{~g}^{-1}, \sim 1200 \mathrm{~mA} \mathrm{~h} \mathrm{~g}{ }^{-1}$ was still maintained. This significant improvement was attributed to the intimate surface coating of PANi on the Si surface, implying that adhesion between binder and Si surface is important to preserve the electrical integrity of the electrode, considering that PANi of the two electrodes is under the same electronic state.

Higgins et al. ${ }^{99}$ used formic acid as secondary dopant for the pre-doped PEDOT:PSS binder for Si electrodes (Si diameter $=$ $60 \mathrm{~nm}$ ). They changed the amount of formic acid from 0 to $20 \mathrm{wt} \%$ with respect to PEDOT:PSS. The electrical conductivity of the electrodes (Si/PEDOT : PSS $=80: 20 \mathrm{wt} \%$ ) increased up to $10 \mathrm{wt} \%$ formic acid and reached a maximum value of $4.2 \mathrm{~S} \mathrm{~cm}^{-1}$ (Fig. 16A). Si/LiPAA/carbon black (80:10:10 wt\%) showed conductivity value of only $1.1 \mathrm{mS} \mathrm{cm}^{-1}$. With fixed amount of formic acid (10 wt\%), the amount of PEDOT:PSS was also varied from 5 to $30 \mathrm{wt} \%$ with respect to $\mathrm{Si}$. The conductivity was further increased from 0.7 to $19 \mathrm{~S} \mathrm{~cm}^{-1}$ (Fig. 16B). Detailed electrochemical
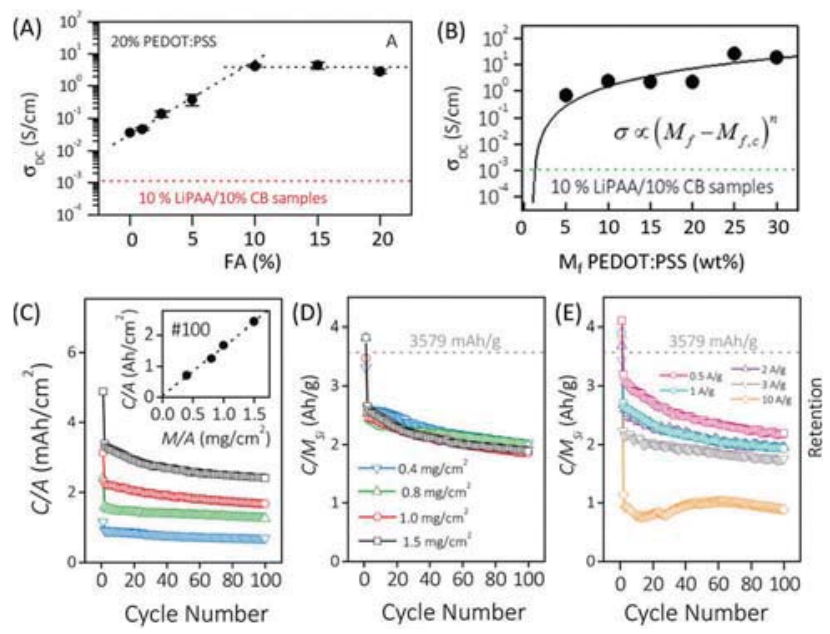

Fig. 16 Electrochemical performance of Si/PEDOT:PSS. (A) Electric conductivity of Si/PEDOT: PSS ( $80: 20$ wt\%) doped with different amounts of formic acid. (B) Electric conductivity of Si electrodes with different amounts of PEDOT:PSS (5-30 wt\%). All PEDOT:PSS was doped with $10 \mathrm{wt} \%$ of formic acid with respect to PEDOT:PSS. (C) Areal capacity and (D) specific capacity of Si/PEDOT : PSS ( $80: 20$ wt\%, 10 wt\% formic acid) with various Si loading amounts from 0.4 to $1.5 \mathrm{mg} \mathrm{cm}^{-2}$. (E) Specific capacity of Si/PEDOT: PSS (80: $20 \mathrm{wt} \%, 10 \mathrm{wt} \%$ formic acid) cycled at different current density from 0.5 to $10 \mathrm{~A} \mathrm{~g} \mathrm{~g}^{-1}$. Adapted with permission from ref. 99. Copyright 2016 American Chemical Society. 
analysis of Si/PEDOT: PSS (80:20 wt $\%$ with $10 \mathrm{wt} \%$ formic acid) revealed its high conductivity. While the specific capacity generally decreases at the high Si loading due to the increased polarization, the specific capacities of Si/PEDOT:PSS were consistent regardless of Si loading amount (Fig. 16C and D). Along with this, excellent rate capability (Fig. 16E) was also achieved by taking advantage of their high conductivity.

\subsection{Side-chain conducting binders}

Park et $a l .{ }^{86}$ developed pyrene-based conductive binders (PPy and PPyE) for Si anodes (Fig. 17A and B). These polymers are distinct from other conductive binders in that they do not have conjugated polymer backbones. Instead, pyrene side groups connected to polyacrylate backbone are self-assembled via $\pi-\pi$ stacking (Fig. 17A and B), allowing the $\pi$-cloud delocalization. Electrons can be transported through this $\pi$-channels. The electron mobility of PPy and PPyE was measured by steadystate space-charge-limited-current method, showing $1.9 \times 10^{-4}$ and $8.5 \times 10^{-4} \mathrm{~cm}^{2} \mathrm{~V}^{-1} \mathrm{~s}^{-1}$, respectively. The higher conductivity of PPyE is ascribed to the more optimized morphology of PPyE by means of ethylene oxide group due to the fact that there is no difference between PPy and PPyE in their lowest energy features as shown (Fig. 17C) by synchron-based X-ray absorption spectroscopy (sXAS) analysis. The cycling stability of Si/PPyE (66.7/33.3 wt\%, Si diameter $<100 \mathrm{~nm})$ was excellent at a low Si loading $\left(0.16 \mathrm{mg} \mathrm{Si} \mathrm{cm}^{-2}\right)$; the capacity of $\sim 1500 \mathrm{~mA} \mathrm{~h} \mathrm{~g}^{-1}$ was preserved after 1000 cycles at a current density of $8.4 \mathrm{~A} \mathrm{~g}^{-1}$ for Si/PPyE (Fig. 17D). Zhao et al. ${ }^{100}$ further improved the adhesion ability of PPy by introducing methacrylic acid monomer.

While there are some promising results, further research in conducting binders is needed to enable their operation at low binder loadings, as higher conducting binder loadings in pursuit of higher conductivity result in a loss in energy density. In addition, there is not much data available to conclude that these polymers can perform well for electrodes with high $\mathrm{Si}$ mass loadings and also for more challenging electrodes such as Si microparticles. Moreover, the redox-active nature of these binders could be problematic for long-term cycling stability. In addition, high stiffness of these polymers originating from their conjugated backbone could limit their ability to respond the changes in the electrode morphology under dynamic conditions. The undesired aggregation of the polymer chains should also be considered.

\section{Impact of topological crosslinking}

The cost reduction in producing $\mathrm{Si}$ particles is critical for the commercial adoption of $\mathrm{Si}$ anodes for lithium-ion batteries. To this end, Si microparticle (SiMP) is advantageous over Si nanoparticle (SiNP) because of its low production cost and diverse availability ${ }^{81}$ such as industrial silicon waste. Nevertheless, it is far more challenging to achieve stable cycling performance for SiMP electrodes because the pulverization becomes more severe with increasing the size of Si particles, accompanied by large stress that ruptures polymeric binders (Fig. 18A). Several strategies have been proposed to resolve the breakage of binders on the basis of the self-healing effect. However, these approaches still pose the limitation for SiMP anodes because pulverized Si particles can be mobile upon breakage of binders and can be electrically isolated with an unstable interface. ${ }^{28}$

Choi et $a{ }^{26}{ }^{26}$ presented a new strategy that highly elastic binder layer surrounding Si microparticles keep pulverized Si particles coalesced during charge/discharge cycling and allow to retain the conductive pathways to whole Si particles (Fig. 18B). To realize this concept, the binder must endure the mechanical stress caused by Si expansion. They were inspired by the working principle of moving pulleys, where the tension of the rope is greatly reduced by distributing and equalizing the localized force (Fig. 18C). ${ }^{101}$ In an effort to realize this principle on a molecular level, they constructed a molecular pulley binder (PR-PAA) by covalently attaching PAA to the ring components of polyrotaxane (PR) as represented in Fig. 18D and E. Consistent with the principle of moving pulleys, the stress applied to the polymer is greatly reduced by ring sliding, which renders PR-PAA highly elastic. These unique properties originate from the topological crosslinking between PAA and PR through the ring molecules, which is neither fixed nor dissociated. In this regard, topological crosslinking combines the best of covalent and noncovalent crosslinking in the form of a mechanical bond embodied in a polyrotaxane crosslinked with PAA. Importantly, even though it is covalently crosslinked, the dynamic nature of the polymer network is still preserved due to the ring-sliding motion of the ring component.

The mechanical properties of PR-PAA were examined by tensile test. The PR-PAA showed high elasticity (390\%) and less strain hysteresis during the repeated stretch-recovery cycles. Its stress-strain curve follows a nonlinear stiffening behavior while all previously reported polymer binders including PAA exhibit nonlinear softening behavior. Nonlinear stiffening is

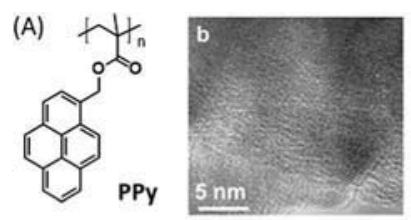

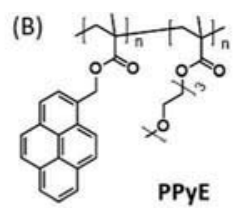

PPyE
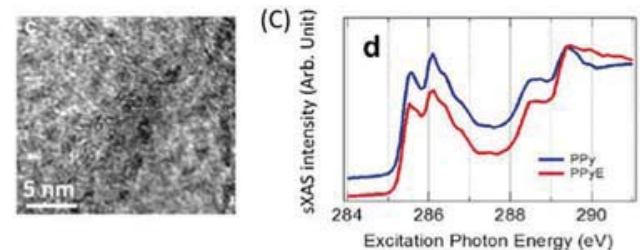

Fig. 17 Chemical structures and transmission electron microscopy (TEM) images of (A) PPy and (B) PPyE. (C) Carbon k-edge sXAS spectra of PPy and PPyE. (D) Cycling performance of Si/PPy and Si/PPyE when cycled at $8.4 \mathrm{~A} \mathrm{~g}^{-1}$. Si : binder $=66.7: 33.3 \mathrm{wt} \%$. The Si loading amount is $0.16 \mathrm{mg} \mathrm{cm}^{-2}$. Adapted with permission from ref. 86. Copyright 2015 American Chemical Society. 
(A)

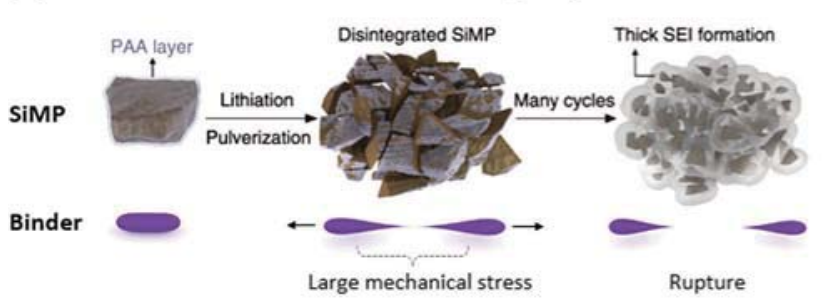

(C)

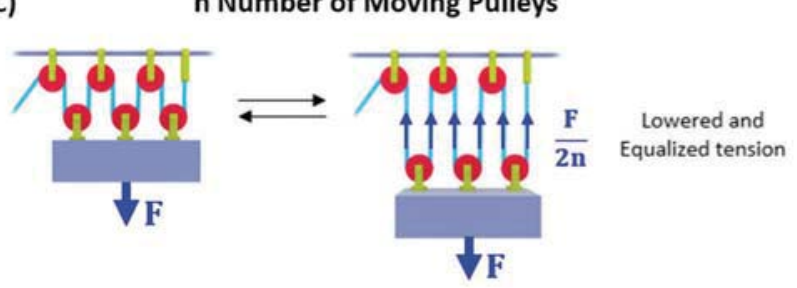

(B)

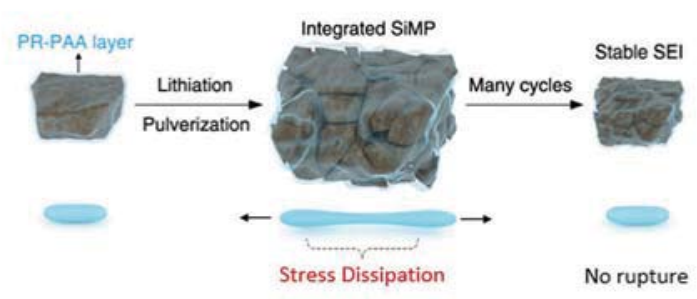

(D)

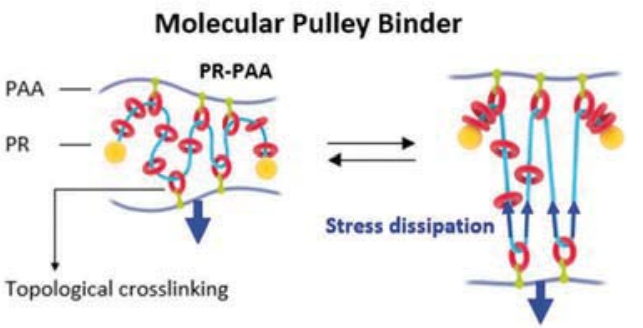

(E)
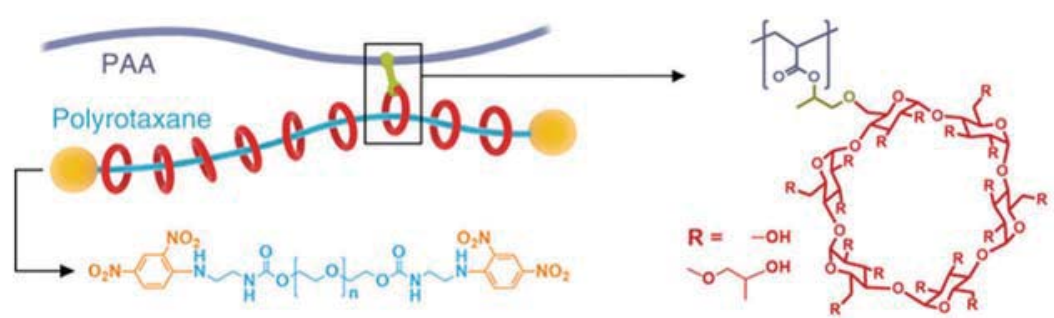

Hydroxypropylated a-cyclodextrin

Fig. 18 Design and working principle of molecular pulley binder (PR-PAA) compared with conventional binders. (A) Failure mechanism of conventional binders (PAA) in SiMP anodes. (B) Working mechanism of elastic binders (PR-PAA) in SiMP anodes. (C) Operational principle of moving pulleys, which leads to a lowered and equalized tension on the rope. (D) Working principle of the molecular pulley binder, PR-PAA, which enables the stress dissipation and high stretchability. (E) Chemical structure of PR-PAA and its schematic representation. Adapted from ref. 26 with permission from AAAS, copyright 2017.

advantageous for $\mathrm{Si}$ anodes; the materials with nonlinear stiffening are highly elastic, accumulate smaller stress with respect to an increase in strain, and efficiently resist against crack propagation. Evidently, similar mechanical properties can be also found in spider silk and arterial walls. They validated that these mechanical properties of PR-PAA can keep the pulverized Si particles coalesced and stabilize the SEI layer by SEM analyses. Importantly, this particular strategy combines covalent crosslinking, high elasticity and supramolecular interactions in one structure, which is quite unique and a substantial improvement compared to earlier reports.

The electrochemical performance of PR-PAA-SiMP anodes corroborated the effect of topological crosslinking. The PR-PAA-SiMP anodes were prepared by containing $80 \mathrm{wt} \%$ SiMP $\left(\right.$ diameter $=2.1 \mu \mathrm{m}$, Si loading $\left.=1.04-1.07 \mathrm{mg} \mathrm{cm}^{-2}\right)$, $10 \mathrm{wt} \%$ conductive agent (Super P), and $10 \mathrm{wt} \%$ binder. PR-PAA-SiMP anode cycled at $0.624 \mathrm{~mA} \mathrm{~h} \mathrm{~cm}^{-2}$ showed a high areal capacity of $2.43 \mathrm{~mA} \mathrm{~cm}^{-2}$ with a good capacity retention of 91\% after 150 cycles. The Coulombic efficiency reached $99.82 \%$ at the 22 nd cycle. When cycled at a higher current density of $1.248 \mathrm{~mA} \mathrm{~h} \mathrm{~cm}^{-2}$, PR-PAA-SiMP anode retained $85 \%$ of the initial capacity after 370 cycles. Remarkably, the electrode swelling of PR-PAA-SiMP was only $20-30 \%$ of that of PAA-SiMP due to the high elasticity of PR-PAA binder. In addition, this particular study shows that properly designed polymeric binders can address issues originating from the pulverization of silicon particles by keeping them coalesced while stabilizing the SEI layer by limiting the exposure of fresh electrode surface.

\section{Conclusion}

As evidenced from various examples in the literature, polymeric binders play a vital role in $\mathrm{Si}$ anodes by preserving the physical integrity of an electrode, stabilizing the electrode-electrolyte interface, and mitigating the side effects of the Si pulverization during the immense volume change of Si. To this end, a large number of investigations has separately examined various polymers by focusing on their chemical bonds, mechanical properties, supramolecular interactions, and electrochemical properties. However, existing studies are rather sporadic and case-specific such that it is difficult to establish an overall design principle of polymeric binders for $\mathrm{Si}$ anodes. In this review, we compiled the important findings from a wide range of literature examples and provide insights for polymer binder design in a systematic and organized fashion. First, the self-healing effect of the strong supramolecular interactions is considered as inevitable requisites for long-term cycle 
performance of $\mathrm{Si}$ anodes because the binder-binder and binder-Si interactions are continuously challenged by formidable mechanical stress of the Si volume expansion. Second, branched structures strengthen the supramolecular interactions by increasing the number of anchoring points. Although a single anchoring point of polymeric binders based on strong supramolecular interactions is still weak, the force distribution toward branched chains reduces the force applied to each anchoring point and the cooperative intrachain cohesion between branched chains reinforces the adhesion strength of the anchoring points. Lastly, topological crosslinking of polymers presents a new connection method for branched structures. The ring-sliding polyrotaxanes greatly lower the mechanical stress applied to each chain, rendering the polymer highly elastic and endowed with unconventional mechanical properties such as nonlinear stiffening. Importantly, it has been demonstrated that the impact of polymeric binders is not limited to morphology control at the particle and electrode levels, but it could also help to alleviate problems associated with Si particle pulverization and SEI layer destabilization. Therefore, the three design principles of polymeric binders for $\mathrm{Si}$ anodes will serve as a solid basis for the Si anodes to advance toward commercially viable technology. On a broader context, the key is to consider battery cells as dynamic matrices wherein the various supramolecular interactions can still take place and all these examples show the promise of supramolecular chemistry and mechanical bonds in the form of polyrotaxanes in emerging energy storage applications. It is also very important to decrease the amount of inactive components because their presence necessarily sacrifice the energy density. Also, the thick binder layer could hinder the transport of lithium ions and electrons. In view of a considerable discrepancy in the binder content between commercial electrodes ( $<3 \mathrm{wt} \%$ binder) and academic level electrodes ( $>10 \mathrm{wt} \%$ binder), the attempt to decrease the binder content is a 'must-do' agenda for successful commercialization. Further studies should certainly be directed towards developing binders for Si/graphite blended electrodes, as the exclusive use of $\mathrm{Si}$ is an unlikely option for commercial products in the near future. Binders targeting $\mathrm{Si} /$ graphite blended electrodes should hold dual functionality capable of interacting with both $\mathrm{Si}$ and graphite simultaneously. Moreover, the binder research should proceed with in situ analyses to better understand various dynamic physicochemical processes of the electrode components. Just like organic reaction mechanisms, we should aim to establish in-depth mechanistic understanding for these dynamic processes. With this critical review article, we hope to stimulate the research in these directions to further advance Si anodes, particularly toward increasing the energy densities of LIBs in portable electronics and EV applications.

\section{Conflicts of interest}

There are no conflicts to declare.

\section{Acknowledgements}

J. W. C. acknowledges the support by the National Research Foundation of Korea (NRF) grant funded by the Korea government (MEST) (NRF-2015R1A2A1A05001737). A. C. thanks for the start-up funds provided by University of Fribourg, Switzerland.

\section{References}

1 B. Dunn, H. Kamath and J. M. Tarascon, Science, 2011, 334, 928-935.

2 J. M. Tarascon and M. Armand, Nature, 2001, 414, 359-367.

3 B. Kang and G. Ceder, Nature, 2009, 458, 190-193.

4 J. W. Choi and D. Aurbach, Nat. Rev. Mater., 2016, 1, 16013. 5 H. Wu and Y. Cui, Nano Today, 2012, 7, 414-429.

6 S. C. Jung, J. W. Choi and Y.-K. Han, Nano Lett., 2012, 12, 5342-5347.

7 H. Ma, F. Cheng, J. Y. Chen, J. Z. Zhao, C. S. Li, Z. L. Tao and J. Liang, Adv. Mater., 2007, 19, 4067-4070.

8 J. M. Yuk, H. K. Seo, J. W. Choi and J. Y. Lee, ACS Nano, 2014, 8, 7478-7485.

9 C. K. Chan, H. Peng, G. Liu, K. McIlwrath, X. F. Zhang, R. A. Huggins and Y. Cui, Nat. Nanotechnol., 2008, 3, 31-35.

10 M.-H. Park, M. G. Kim, J. Joo, K. Kim, J. Kim, S. Ahn, Y. Cui and J. Cho, Nano Lett., 2009, 9, 3844-3847.

11 T. Song, J. Xia, J.-H. Lee, D. H. Lee, M.-S. Kwon, J.-M. Choi, J. Wu, S. K. Doo, H. Chang, W. I. Park, D. S. Zang, H. Kim, Y. Huang, K.-C. Hwang, J. A. Rogers and U. Paik, Nano Lett., 2010, 10, 1710-1716.

12 Y. Yao, M. T. McDowell, I. Ryu, H. Wu, N. Liu, L. Hu, W. D. Nix and Y. Cui, Nano Lett., 2011, 11, 2949-2954.

13 T. H. Hwang, Y. M. Lee, B.-S. Kong, J.-S. Seo and J. W. Choi, Nano Lett., 2012, 12, 802-807.

14 J.-K. Yoo, J. Kim, Y. S. Jung and K. Kang, Adv. Mater., 2012, 24, 5452-5456.

15 X. Li, M. Gu, S. Hu, R. Kennard, P. Yan, X. Chen, C. Wang, M. J. Sailor, J.-G. Zhang and J. Liu, Nat. Commun., 2014, $5,4105$.

16 N. Liu, Z. Lu, J. Zhao, M. T. McDowell, H.-W. Lee, W. Zhao and Y. Cui, Nat. Nanotechnol., 2014, 9, 187-192.

17 C. Pereira-Nabais, J. Światowska, A. Chagnes, A. Gohier, S. Zanna, A. Seyeux, P. Tran-Van, C.-S. Cojocaru, M. Cassir and P. Marcus, J. Phys. Chem. C, 2014, 118, 2919-2928.

18 T. Jaumann, M. Herklotz, M. Klose, K. Pinkert, S. Oswald, J. Eckert and L. Giebeler, Chem. Mater., 2015, 27, 37-43.

19 J. Liang, X. Li, Q. Cheng, Z. Hou, L. Fan, Y. Zhu and Y. Qian, Nanoscale, 2015, 7, 3440-3444.

20 Z. D. Lu, N. Liu, H. W. Lee, J. Zhao, W. Y. Li, Y. Z. Li and Y. Cui, ACS Nano, 2015, 9, 2540-2547.

21 M. Ko, S. Chae, J. Ma, N. Kim, H.-W. Lee, Y. Cui and J. Cho, Nat. Energy, 2016, 1, 16113.

22 Y. Li, K. Yan, H.-W. Lee, Z. Lu, N. Liu and Y. Cui, Nat. Energy, 2016, 1, 15029.

23 S. Choi, D. S. Jung and J. W. Choi, Nano Lett., 2014, 14, 7120-7125. 
24 I. H. Son, J. Hwan Park, S. Kwon, S. Park, M. H. Rümmeli, A. Bachmatiuk, H. J. Song, J. Ku, J. W. Choi, J.-m. Choi, S.-G. Doo and H. Chang, Nat. Commun., 2015, 6, 7393.

25 X. H. Liu, L. Zhong, S. Huang, S. X. Mao, T. Zhu and J. Y. Huang, ACS Nano, 2012, 6, 1522-1531.

26 S. Choi, T.-w. Kwon, A. Coskun and J. W. Choi, Science, 2017, 357, 279-283.

27 J. S. Bridel, T. Azais, M. Morcrette, J. M. Tarascon and D. Larcher, J. Electrochem. Soc., 2011, 158, A750-A759.

28 Z. Chen, C. Wang, J. Lopez, Z. Lu, Y. Cui and Z. Bao, Adv. Energy Mater., 2015, 5, 1401826.

29 Y. Sun, J. Lopez, H.-W. Lee, N. Liu, G. Zheng, C.-L. Wu, J. Sun, W. Liu, J. W. Chung, Z. Bao and Y. Cui, Adv. Mater., 2016, 28, 2455-2461.

30 C. Wang, H. Wu, Z. Chen, M. T. McDowell, Y. Cui and Z. Bao, Nat. Chem., 2013, 5, 1042-1048.

31 T.-w. Kwon, Y. K. Jeong, I. Lee, T.-S. Kim, J. W. Choi and A. Coskun, Adv. Mater., 2014, 26, 7979-7985.

32 C. Hwang, S. Joo, N. R. Kang, U. Lee, T. H. Kim, Y. Jeon, J. Kim, Y. J. Kim, J. Y. Kim, S. K. Kwak and H. K. Song, Sci. Rep., 2015, 5, 14433.

33 J.-H. Lee, S. Lee, U. Paik and Y.-M. Choi, J. Power Sources, 2005, 147, 249-255.

34 J.-H. Lee, U. Paik, V. A. Hackley and Y.-M. Choi, J. Electrochem. Soc., 2005, 152, A1763-A1769.

35 Z. H. Chen, L. Christensen and J. R. Dahn, J. Electrochem. Soc., 2003, 150, A1073-A1078.

36 Z. Chen, L. Christensen and J. R. Dahn, Electrochem. Commun., 2003, 5, 919-923.

37 W. R. Liu, M. H. Yang, H. C. Wu, S. M. Chiao and N. L. Wu, Electrochem. Solid-State Lett., 2005, 8, A100-A103.

38 H. Buqa, M. Holzapfel, F. Krumeich, C. Veit and P. Novák, J. Power Sources, 2006, 161, 617-622.

39 L. B. Chen, X. H. Xie, J. Y. Xie, K. Wang and J. Yang, J. Appl. Electrochem., 2006, 36, 1099-1104.

$40 \mathrm{~J} . \mathrm{Li}, \mathrm{R}$. B. Lewis and J. R. Dahn, Electrochem. Solid-State Lett., 2007, 10, A17-A20.

41 B. Lestrie, S. Bahri, I. Sandu, L. Roue and D. Guyomard, Electrochem. Commun., 2007, 9, 2801-2806.

42 J. S. Bridel, T. Azaïs, M. Morcrette, J. M. Tarascon and D. Larcher, Chem. Mater., 2010, 22, 1229-1241.

43 J. C. Guo and C. S. Wang, Chem. Commun., 2010, 46, 1428-1430.

44 W. C. Cho, H. J. Kim, H. I. Lee, M. W. Seo, H. W. Ra, S. J. Yoon, T. Y. Mun, Y. K. Kim, J. H. Kim, B. H. Kim, J. W. Kook, C.-Y. Yoo, J. G. Lee and J. W. Choi, Nano Lett., 2016, 16, 7261-7269.

45 H. M. Jeong, S. Y. Lee, W. H. Shin, J. H. Kwon, A. Shakoor, T. H. Hwang, S. Y. Kim, B.-S. Kong, J.-S. Seo, Y. M. Lee, J. K. Kang and J. W. Choi, RSC Adv., 2012, 2, 4311-4317.

46 D. S. Jung, T. H. Hwang, S. B. Park and J. W. Choi, Nano Lett., 2013, 13, 2092-2097.

47 A. Magasinski, B. Zdyrko, I. Kovalenko, B. Hertzberg, R. Burtovyy, C. F. Huebner, T. F. Fuller, I. Luzinov and G. Yushin, ACS Appl. Mater. Interfaces, 2010, 2, 3004-3010.
48 S. Komaba, K. Shimomura, N. Yabuuchi, T. Ozeki, H. Yui and K. Konno, J. Phys. Chem. C, 2011, 115, 13487-13495.

49 H. J. Kim, S. Choi, S. J. Lee, M. W. Seo, J. G. Lee, E. Deniz, Y. J. Lee, E. K. Kim and J. W. Choi, Nano Lett., 2016, 16, 282-288.

50 I. Kovalenko, B. Zdyrko, A. Magasinski, B. Hertzberg, Z. Milicev, R. Burtovyy, I. Luzinov and G. Yushin, Science, 2011, 334, 75-79.

51 M. H. Ryou, J. Kim, I. Lee, S. Kim, Y. K. Jeong, S. Hong, J. H. Ryu, T. S. Kim, J. K. Park, H. Lee and J. W. Choi, Adv. Mater., 2013, 25, 1571-1576.

52 H. Lee, N. F. Scherer and P. B. Messersmith, Proc. Natl. Acad. Sci. U. S. A., 2006, 103, 12999-13003.

53 J. Liu, Q. Zhang, T. Zhang, J.-T. Li, L. Huang and S.-G. Sun, Adv. Funct. Mater., 2015, 25, 3599-3605.

54 R. Kuruba, M. K. Datta, K. Damodaran, P. H. Jampani, B. Gattu, P. P. Patel, P. M. Shanthi, S. Damle and P. N. Kumta, J. Power Sources, 2015, 298, 331-340.

55 J. Xu, L. Zhang, Y. Wang, T. Chen, M. Al-Shroofy and Y.-T. Cheng, ACS Appl. Mater. Interfaces, 2017, 9, 3562-3569.

56 J. Li, L. Christensen, M. N. Obrovac, K. C. Hewitt and J. R. Dahn, J. Electrochem. Soc., 2008, 155, A234-A238.

57 B. N. Balzer, S. Kienle, M. Gallei, R. von Klitzing, M. Rehahn and T. Hugel, Soft Mater., 2014, 12, S106-S114.

58 B. N. Balzer, M. Gallei, M. V. Hauf, M. Stallhofer, L. Wiegleb, A. Holleitner, M. Rehahn and T. Hugel, Angew. Chem., Int. Ed., 2013, 52, 6541-6544.

59 S. Kienle, M. Gallei, H. Yu, B. Zhang, S. Krysiak, B. N. Balzer, M. Rehahn, A. D. Schlüter and T. Hugel, Langmuir, 2014, 30, 4351-4357.

60 Y. K. Jeong, T.-w. Kwon, I. Lee, T.-S. Kim, A. Coskun and J. W. Choi, Nano Lett., 2014, 14, 864-870.

61 M. Murase, N. Yabuuchi, Z. J. Han, J. Y. Son, Y. T. Cui, H. Oji and S. Komaba, ChemSusChem, 2012, 5, 2307-2311.

62 L. Wei, C. Chen, Z. Hou and H. Wei, Sci. Rep., 2016, 6, 19583.

63 J.-I. Lee, H. Kang, K. H. Park, M. Shin, D. Hong, H. J. Cho, N.-R. Kang, J. Lee, S. M. Lee, J.-Y. Kim, C. K. Kim, H. Park, N.-S. Choi, S. Park and C. Yang, Small, 2016, 12, 3119-3127.

64 R. R. Garsuch, D.-B. Le, A. Garsuch, J. Li, S. Wang, A. Farooq and J. R. Dahn, J. Electrochem. Soc., 2008, 155, A721-A724.

65 J. Xu, Q. Zhang and Y.-T. Cheng, J. Electrochem. Soc., 2016, 163, A401-A405.

66 B. Koo, H. Kim, Y. Cho, K. T. Lee, N. S. Choi and J. Cho, Angew. Chem., Int. Ed., 2012, 51, 8762-8767.

67 J. X. Song, M. J. Zhou, R. Yi, T. Xu, M. L. Gordin, D. H. Tang, Z. X. Yu, M. Regula and D. H. Wang, Adv. Funct. Mater., 2014, 24, 5904-5910.

68 M. T. Jeena, J.-I. Lee, S. H. Kim, C. Kim, J.-Y. Kim, S. Park and J.-H. Ryu, ACS Appl. Mater. Interfaces, 2014, 6, 18001-18007.

69 Z.-J. Han, N. Yabuuchi, S. Hashimoto, T. Sasaki and S. Komaba, ECS Electrochem. Lett., 2013, 2, A17-A20.

70 C. Chen, S. H. Lee, M. Cho, J. Kim and Y. Lee, ACS Appl. Mater. Interfaces, 2016, 8, 2658-2665. 
71 Z. Liu, S. Han, C. Xu, Y. Luo, N. Peng, C. Qin, M. Zhou, W. Wang, L. Chen and S. Okada, RSC Adv., 2016, 6, 68371-68378.

72 Y. Park, S. Lee, S.-H. Kim, B. Y. Jang, J. S. Kim, S. M. Oh, J.-Y. Kim, N.-S. Choi, K. T. Lee and B.-S. Kim, RSC Adv., 2013, 3, 12625-12630.

73 S. Aoki, Z.-J. Han, K. Yamagiwa, N. Yabuuchi, M. Murase, K. Okamoto, T. Kiyosu, M. Satoh and S. Komaba, J. Electrochem. Soc., 2015, 162, A2245-A2249.

74 J. Lopez, Z. Chen, C. Wang, S. C. Andrews, Y. Cui and Z. Bao, ACS Appl. Mater. Interfaces, 2016, 8, 2318-2324.

75 Y. K. Jeong, T.-w. Kwon, I. Lee, T.-S. Kim, A. Coskun and J. W. Choi, Energy Environ. Sci., 2015, 8, 1224-1230.

76 S. Klamor, M. Schroder, G. Brunklaus, P. Niehoff, F. Berkemeier, F. M. Schappacher and M. Winter, Phys. Chem. Chem. Phys., 2015, 17, 5632-5641.

77 C. J. Ferris, K. J. Gilmore, G. G. Wallace and M. i. h. Panhuis, Soft Mater., 2013, 9, 3705-3711.

78 T.-w. Kwon, Y. K. Jeong, E. Deniz, S. Y. AlQaradawi, J. W. Choi and A. Coskun, ACS Nano, 2015, 9, 11317-11324.

79 T. Kakuta, Y. Takashima, T. Sano, T. Nakamura, Y. Kobayashi, H. Yamaguchi and A. Harada, Macromolecules, 2015, 48, 732-738.

80 J. Liu, Q. Zhang, Z.-Y. Wu, J.-H. Wu, J.-T. Li, L. Huang and S.-G. Sun, Chem. Commun., 2014, 50, 6386-6389.

81 L. Zhang, L. Zhang, L. Chai, P. Xue, W. Hao and H. Zheng, J. Mater. Chem. A, 2014, 2, 19036-19045.

82 J. Yoon, D. X. Oh, C. Jo, J. Lee and D. S. Hwang, Phys. Chem. Chem. Phys., 2014, 16, 25628-25635.

83 S. Lim, H. Chu, K. Lee, T. Yim, Y.-J. Kim, J. Mun and T.-H. Kim, ACS Appl. Mater. Interfaces, 2015, 7, 23545-23553.

84 G. Liu, S. Xun, N. Vukmirovic, X. Song, P. Olalde-Velasco, H. Zheng, V. S. Battaglia, L. Wang and W. Yang, Adv. Mater., 2011, 23, 4679-4683.

85 H. Wu, G. Yu, L. Pan, N. Liu, M. T. McDowell, Z. Bao and Y. Cui, Nat. Commun., 2013, 4, 1943.

86 S.-J. Park, H. Zhao, G. Ai, C. Wang, X. Song, N. Yuca, V. S. Battaglia, W. Yang and G. Liu, J. Am. Chem. Soc., 2015, 137, 2565-2571.
87 P. Sengodu and A. D. Deshmukh, RSC Adv., 2015, 5, 42109-42130.

88 Y. Liu, T. Matsumura, N. Imanishi, A. Hirano, T. Ichikawa and Y. Takeda, Electrochem. Solid-State Lett., 2005, 8, A599-A602.

89 H.-S. La, K.-S. Park, K.-S. Nahm, K.-K. Jeong and Y.-S. Lee, Colloids Surf., A, 2006, 272, 22-26.

90 S. Y. Chew, Z. P. Guo, J. Z. Wang, J. Chen, P. Munroe, S. H. Ng, L. Zhao and H. K. Liu, Electrochem. Commun., 2007, 9, 941-946.

91 L. Yue, S. Wang, X. Zhao and L. Zhang, J. Mater. Chem., 2012, 22, 1094-1099.

92 F. M. Courtel, S. Niketic, D. Duguay, Y. Abu-Lebdeh and I. J. Davidson, J. Power Sources, 2011, 196, 2128-2134.

93 M. Wu, X. Xiao, N. Vukmirovic, S. Xun, P. K. Das, X. Song, P. Olalde-Velasco, D. Wang, A. Z. Weber, L.-W. Wang, V. S. Battaglia, W. Yang and G. Liu, J. Am. Chem. Soc., 2013, 135, 12048-12056.

94 D. Liu, Y. Zhao, R. Tan, L.-L. Tian, Y. Liu, H. Chen and F. Pan, Nano Energy, 2017, 36, 206-212.

95 H. Zhao, Z. Wang, P. Lu, M. Jiang, F. Shi, X. Song, Z. Zheng, X. Zhou, Y. Fu, G. Abdelbast, X. Xiao, Z. Liu, V. S. Battaglia, K. Zaghib and G. Liu, Nano Lett., 2014, 14, 6704-6710.

96 H. Zhao, N. Yuca, Z. Zheng, Y. Fu, V. S. Battaglia, G. Abdelbast, K. Zaghib and G. Liu, ACS Appl. Mater. Interfaces, 2015, 7, 862-866.

97 S.-M. Kim, M. H. Kim, S. Y. Choi, J. G. Lee, J. Jang, J. B. Lee, J. H. Ryu, S. S. Hwang, J.-H. Park, K. Shin, Y. G. Kim and S. M. Oh, Energy Environ. Sci., 2015, 8, 1538-1543.

98 N. Salem, M. Lavrisa and Y. Abu-Lebdeh, Energy Technol., 2016, 4, 331-340.

99 T. M. Higgins, S.-H. Park, P. J. King, C. Zhang, N. McEvoy, N. C. Berner, D. Daly, A. Shmeliov, U. Khan, G. Duesberg, V. Nicolosi and J. N. Coleman, ACS Nano, 2016, 10, 3702-3713.

100 H. Zhao, Y. Wei, R. Qiao, C. Zhu, Z. Zheng, M. Ling, Z. Jia, Y. Bai, Y. Fu, J. Lei, X. Song, V. S. Battaglia, W. Yang, P. B. Messersmith and G. Liu, Nano Lett., 2015, 15, 7927-7932.

101 J. Ryu and S. Park, Science, 2017, 357, 250-251. 